\title{
金属催化的碳-杂键对炔键的加成反应研究进展
}

\author{
赵飞 ${ }^{a}$ 贾秀稳 ${ }^{a}$ 王东萍 ${ }^{a}$ 费朝丽 ${ }^{a}$ \\ 吴成林 ${ }^{b, c}$ 王 江 ${ }^{b, c}$ 柳 红*,b,c \\ ( ${ }^{a}$ 成都大学四川抗菌素工业研究所 抗生素研究与再评价四川省重点实验室 成都 610052) \\ ( ${ }^{b}$ 中国科学院上海药物研究所 受体结构与功能重点实验室 上海 201203) \\ ( ${ }^{c}$ 中国科学院大学 北京 100049)
}

\begin{abstract}
摘要 碳一杂键对炔键的加成反应已经成为对碳碳参键进行官能团化的一种重要手段, 此类反应可以一步快速构建两 个化学键即一个碳一碳键和一个碳一杂键, 因而具有反应效率高、原子经济性高的特点. 近年来, $\mathrm{Al}, \mathrm{Fe}, \mathrm{Ni}, \mathrm{Cu}, \mathrm{Ga}, \mathrm{Ru}$, $\mathrm{Rh}, \mathrm{Pd}, \mathrm{Hf}, \mathrm{Ir}, \mathrm{Pt}, \mathrm{Au}, \mathrm{Bi}$ 等催化的诸多类型的碳一杂键对炔键的加成反应取得了重要进展. 根据对炔键进行加成的碳一杂 键的类型分为 $\mathrm{C}-\mathrm{H}, \mathrm{C}-\mathrm{B}, \mathrm{C}-\mathrm{N}, \mathrm{C}-\mathrm{O}, \mathrm{C}-\mathrm{Si}, \mathrm{C}-\mathrm{S}, \mathrm{C}-\mathrm{X}(\mathrm{X}=\mathrm{Cl}, \mathrm{Br}, \mathrm{I}), \mathrm{C}-\mathrm{Se}$ 键这 8 类逐一进行介绍, 并对各类加 成反应的反应条件、反应选择性(区域选择性和立体化学选择性)以及反应机理进行了讨论和总结.
\end{abstract}

关键词 金属催化; 碳-杂键; 炔; 加成反应

\section{Research Progress in Metal-Catalyzed Addition of Carbon-Hetero Bonds to Alkynes}

\author{
Zhao, $\mathrm{Fei}^{a}$ \\ Jia, Xiuwen ${ }^{a}$ \\ Wang, Dongping ${ }^{a}$ \\ Fei, Chaoli ${ }^{a}$ \\ $\mathrm{Wu}$, Chenglin ${ }^{b, c}$ \\ Wang, Jiang ${ }^{b, c}$ \\ Liu, Hong ${ }^{*, b, c}$ \\ ( ${ }^{a}$ Antibiotics Research and Re-evaluation Key Laboratory of Sichuan Province, Sichuan Industrial Institute of Antibiotics, \\ Chengdu University, Chengdu 610052) \\ ( ${ }^{b}$ Key Laboratory of Receptor Research, Shanghai Institute of Materia Medica, Chinese Academy of Sciences, \\ Shanghai 201203) \\ ( ${ }^{c}$ University of Chinese Academy of Sciences, Beijing 100049)
}

\begin{abstract}
The addition of carbon-hetero bonds to alkynes has become an important apporach for the functionalization of carbon-carbon triple bonds. It can construct two bonds, namely one carbon-carbon bond and one carbon-hetero bond, in a single one step. These addition reactions feature high efficiency and high atom-economy. In recent years, metal-catalyzed (Al, $\mathrm{Fe}, \mathrm{Ni}, \mathrm{Cu}, \mathrm{Ga}, \mathrm{Ru}, \mathrm{Rh}, \mathrm{Pd}, \mathrm{Hf}, \mathrm{Ir}, \mathrm{Pt}, \mathrm{Au}, \mathrm{Bi}$, etc.) addition of many various kinds of carbon-hetero bonds to alkynes has achieved lots of important developments. According to the types of carbon-hetero bonds, the addition of 8 different kinds of carbon-hetero bonds $[\mathrm{C}-\mathrm{H}, \mathrm{C}-\mathrm{B}, \mathrm{C}-\mathrm{N}, \mathrm{C}-\mathrm{O}, \mathrm{C}-\mathrm{Si}, \mathrm{C}-\mathrm{S}, \mathrm{C}-\mathrm{X}(\mathrm{X}=\mathrm{Cl}, \mathrm{Br}, \mathrm{I}), \mathrm{C}-\mathrm{Se}]$ to alkynes is reviewed in this paper, and the reaction conditions, reaction selectivities (regioselectivities and stereoselectivities) and reaction mechanisms are also discussed and summarized.

Keywords metal-catalyzed; carbon-hetero bonds; alkynes; addition reactions
\end{abstract}

炔键的加成反应是快速而高效地实现对炔键官能 团化的一种重要有机合成策略 ${ }^{[1]}$, 然而传统的加成反应 仅局限于简单的小分子，如 $\mathrm{H}_{2}, \mathrm{HX}(\mathrm{X}=\mathrm{F}, \mathrm{Cl}, \mathrm{Br}), \mathrm{X}_{2}$ $(\mathrm{X}=\mathrm{F}, \mathrm{Cl}, \mathrm{Br}), \mathrm{H}_{2} \mathrm{O}, \mathrm{HCN}, \mathrm{NH}_{3}, \mathrm{BH}_{3}, \mathrm{MeOH}$ 等(Scheme
1), 而且加成反应的形式仅局限于分子间加成，这从一 定程度上限制了加成反应的应用范围. 近年来, 随着合 成方法学的不断发展，有机化学家们发展了金属催化的 更加复杂的小分子对炔键的加成反应(Scheme 1), 反应

* Corresponding author. E-mail: hliu@mail.shcnc.ac.cn

Received July 21, 2016; revised October 14, 2016; published online November 3, 2016.

Project supported by the National Natural Science Foundation of China (Nos. 21602022, 21372235) and the Open Project Program of Antibiotics Research and Re-evaluation Key Laboratory of Sichuan Province (No. ARRLKF15-01).

国家自然科学基金(Nos. 21602022, 21372235) 和抗生素研究与再评价四川省重点实验室开放课题(No. ARRLKF15-01)资助项目. 
既可以发生在分子间, 也可以发生在分子内, 这极大程 度地丰富了加成反应的内涵并拓展了加成反应的应用 范围. 从断键和成键的角度看, 金属催化的碳一杂键对 炔键的加成反应可以一步快速构建两个化学键, 即一个 碳一碳键和一个碳一杂键, 高效地实现对炔键的官能团 化, 而且此类反应具有操作简单、催化效率高、原子经 济性高、底物适用范围广等特点. 近年来, 有机化学家 们发展了多种金属如 $\mathrm{Al}, \mathrm{Fe}, \mathrm{Ni}, \mathrm{Cu}, \mathrm{Ga}, \mathrm{Ru}, \mathrm{Rh}, \mathrm{Pd}, \mathrm{Hf}$, $\mathrm{Ir}, \mathrm{Pt}, \mathrm{Au}, \mathrm{Bi}$ 等催化的诸多类型的碳-杂键对炔键的加成 反应. 本文根据对炔键进行加成的碳一杂键的类型分为 $\mathrm{C}-\mathrm{H}, \mathrm{C}-\mathrm{B}, \mathrm{C}-\mathrm{N}, \mathrm{C}-\mathrm{O}, \mathrm{C}-\mathrm{Si}, \mathrm{C}-\mathrm{S}, \mathrm{C}-\mathrm{X}(\mathrm{X}=\mathrm{Cl}$, $\mathrm{Br}, \mathrm{I}), \mathrm{C}-\mathrm{Se}$ 键这 8 类逐一进行介绍.

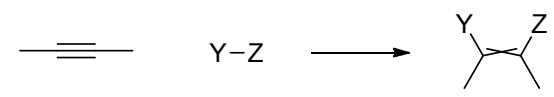

$\mathrm{Y}-\mathrm{Z}: \quad \mathrm{H}-\mathrm{H}, \mathrm{H}-\mathrm{X}, \mathrm{X}-\mathrm{X}, \mathrm{H}-\mathrm{OH}, \mathrm{H}-\mathrm{CN}, \mathrm{H}-\mathrm{NH}_{2}, \mathrm{H}-\mathrm{BH}_{2}, \mathrm{H}-\mathrm{OMe} \cdots$

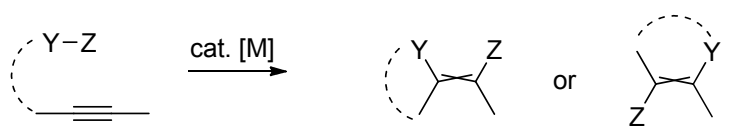

$[\mathrm{M}]=\mathrm{Al}, \mathrm{Fe}, \mathrm{Ni}, \mathrm{Cu}, \mathrm{Ga}, \mathrm{Ru}, \mathrm{Rh}, \mathrm{Pd}, \mathrm{Hf}, \mathrm{Ir}, \mathrm{Pt}, \mathrm{Au}, \mathrm{Bi}$, etc.

$\mathrm{Y}, \mathrm{Z}=\mathrm{H}, \mathrm{B}, \mathrm{C}, \mathrm{N}, \mathrm{O}, \mathrm{Si}, \mathrm{S}, \mathrm{Cl}, \mathrm{Br}, \mathrm{I}, \mathrm{Se}$

图式 1 传统的简单小分子对炔键的加成反应以及当代金属 催化的碳一杂键对炔键的加成反应

Scheme 1 Traditional addition of simple molecules to alkynes and modern metal-catalyzed addition of carbon-hetero bonds to alkynes

\section{1 碳一杂键对炔键的加成}

\section{$1.1 \mathrm{C}-\mathrm{H}$ 键对炔键的加成}

$\mathrm{C}-\mathrm{H}$ 键的键能较大, 要实现其对炔键的加成具有 一定的挑战性, 往往需要金属催化剂对 $\mathrm{C}-\mathrm{H}$ 键进行活 化后方能实现对炔键的加成. 2005 年, Takemoto 课题 组 ${ }^{[2]}$ 首次实现了铑催化的 $\mathrm{C}-\mathrm{H}$ 键 (醛氢键)对炔键的分 子内加成(Scheme 2). 当以含有炔键的脂肪链状甲酰胺 类化合物 1 为底物, 以 $\mathrm{Rh}_{4}(\mathrm{CO})_{12}$ 为催化剂时, 于二甲苯 中在 $130{ }^{\circ} \mathrm{C}$ 反应 $10 \mathrm{~h}$ 即可以较好的收率只得到 $E$ 式目 标产物 2 (Scheme 2). 该反应同样适用于邻炔基苯胺类 底物 3, 这类底物的反应活性更高, 以 $\mathrm{Rh}_{4}(\mathrm{CO})_{12}$ 为催化 剂, 只需要在甲苯中于 $100{ }^{\circ} \mathrm{C}$ 反应 $6 \mathrm{~h}$ 即可以较高的收 率得到目标产物 4 , 但此类底物参与反应时立体选择性 较底物 1 稍差, $E$ 式产物和 $Z$ 式产物的比例在 $2.4: 1$ 到 12.5: 1 之间(Scheme 2), 此反应可能的反应机理如 Scheme 3 所示, 铑催化剂首先与底物中的炔键配合生成 中间体 $\mathbf{A 1}$, 然后铑对 $\mathrm{C}-\mathrm{H}$ 键进行氧化插入生成中间体 B1, 随后 $\mathrm{Rh}-\mathrm{H}$ 键对炔键进行加成(顺式加成为主)得到 中间体 C1, C1 经过还原消除即可得到产物并释放出催
化剂，进行下一轮的催化循环. Takemoto 报道的合成方 法具有操作简单、立体选择性高等特点, 为合成吡咯烷 酮和氧化吲哚类化合物提供了新思路.
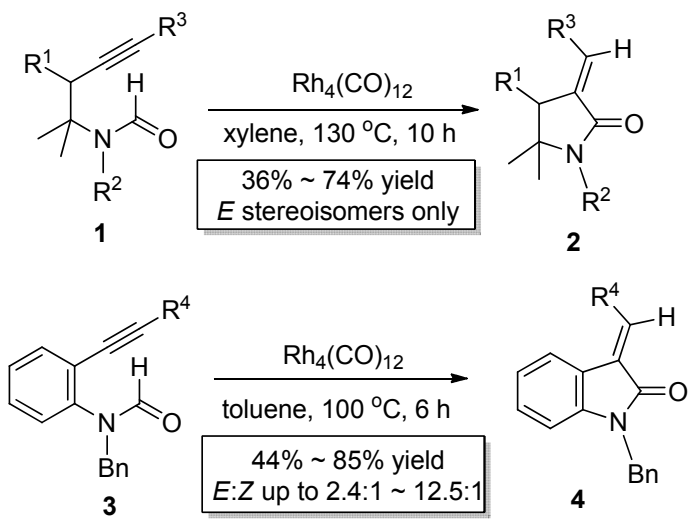

图式 2 铑催化 $\mathrm{C}-\mathrm{H}$ 键对炔键的分子内加成 Scheme 2 Rh-catalyzed intramolecular addition of $\mathrm{C}-\mathrm{H}$ bond to alkynes

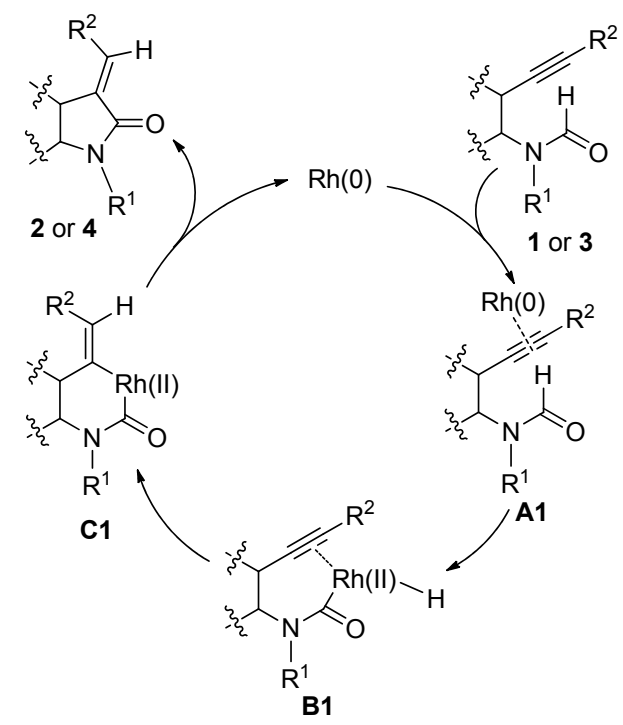

图式 3 铑催化 $\mathrm{C}-\mathrm{H}$ 键对炔键的分子内加成反应机理 Scheme 3 Proposed reaction mechanism of Rh-catalyzed intramolecular addition of $\mathrm{C}-\mathrm{H}$ bond to alkynes

2009 年, Hiyama 小组 ${ }^{[3]}$ 报道了 $\mathrm{Ni}(\mathrm{COD})_{2}$ 和 Lewis 酸 $\left(\mathrm{AlMe}_{3}\right.$ 或 $\left.\mathrm{BPh}_{3}\right)$ 共催化的甲酰胺类化合物 $\mathbf{5}$ 中的醛氢 键对炔 6 的分子间加成(Eq. 1), 该反应区域选择性极好, 当使用非对称炔烃时，酰胺基团只加成到位阻较小的炔 碳上; 该反应的立体化学选择性也非常好, 主要以顺式 加成的形式得到 $E$ 式 $\alpha, \beta$-不饱和酰胺类化合物 7 .

继 Hiyama 小组的工作之后, Tsuji 小组 ${ }^{[4]}$ 几乎同时独 立报道了甲酰胺类化合物 $\mathbf{8}$ 中的醛氢键对炔 $\mathbf{9}$ 的分子间 加成 $(\mathrm{Scheme} 4)$. 该反应以 $\mathrm{PdCl}_{2}(\mathrm{PhCN})_{2}$ 为催化剂, Xantphos 为配体, $\mathrm{PhCOCl}$ 为添加剂, 在三甲苯中于 140 

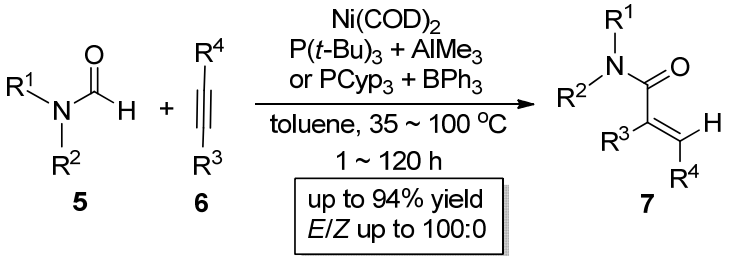

(1)

${ }^{\circ} \mathrm{C}$ 反应 $20 \mathrm{~h}$ 即可以高收率得到目标产物 $\mathbf{1 0}$. 值得一提 的是, 添加剂 $\mathrm{PhCOCl}$ 在反应中扮演着至关重要的角色, 不可或缺, 这可能是因为 $\mathrm{PhCOCl}$ 与甲酰胺底物 $\mathbf{8}$ 发生 反应进而产生 $\mathrm{HCl}, \mathrm{HCl}$ 进一步与钯催化剂反应产生 “Pd-H” 物种，该 “Pd-H” 物种能推动整个催化循环 ${ }^{[4,5]}$. 此反应最大特点是区域选择性好、立体选择性高 $(E$ : $Z=94 ： 6 \sim 100 ： 0$ ). 当使用非末端对称炔烃时, 反应 几乎只得到 $E$ 式产物; 当使用非末端不对称炔烃时, 反 应仅得到单一区域选择性产物, 酰胺基团只加成到位阻 较小的炔碳上, 且几乎只得到 $E$ 式产物(Scheme 4); 当 使用末端炔烃 12 时, 反应主要得到端烯加成产物 13 (Scheme 4). 此反应的加成产物是 $\alpha, \beta$-不饱和酰胺类化 合物, 是一类重要的 Michael 受体, 也是一类重要的有 机中间体.
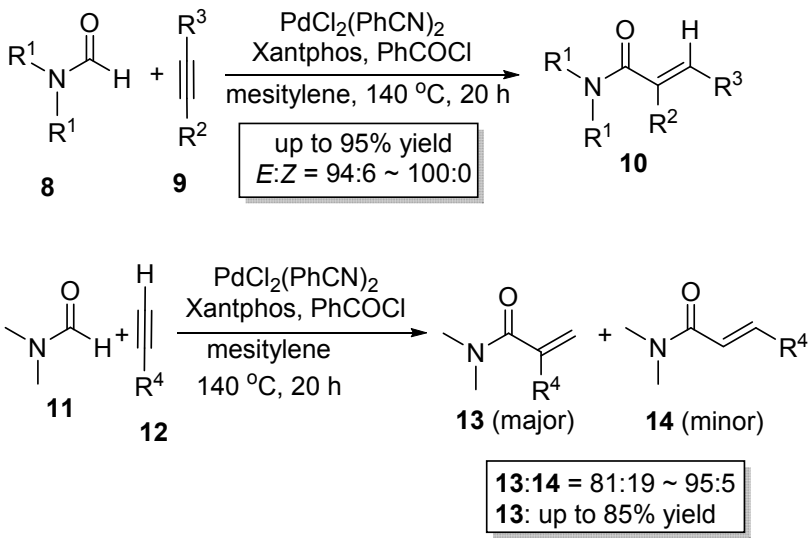

图式 4 钯催化 $\mathrm{C}-\mathrm{H}$ 键对炔键的分子间加成 Scheme 4 Pd-catalyzed intermolecular addition of $\mathrm{C}-\mathrm{H}$ bond to alkynes

2011 年, Trost 小组 ${ }^{[6,7]}$ 以 $\mathrm{Pd}(\mathrm{OAc})_{2}$ 为催化剂实现了 炔 15 中的 $\mathrm{C}-\mathrm{H}$ 键对炔丙酸酯 16 的分子间加成(Scheme 5), 该反应具有专一的区域选择性和立体化学选择性, 以顺式加成的形式得到了高度官能团化的烯炔类产物 17, 产物 17 可以进一步关环得到多取代的吡咯类化合 物. 随后, $\mathrm{Xu}$ 小组 ${ }^{[8]}$ 也报道了类似的工作, 他们以 $[\mathrm{Rh}(\mathrm{COD}) \mathrm{Cl}]_{2}$ 为催化剂实现了炔 $\mathbf{1 8}$ 中的 $\mathrm{C}-\mathrm{H}$ 键对炔 丙醇(醚)19 或炔丙胺 21 的分子间加成(Scheme 5), 以专 一的区域选择性和立体化学选择性分别得到了烯炔类 产物 20 或 22.

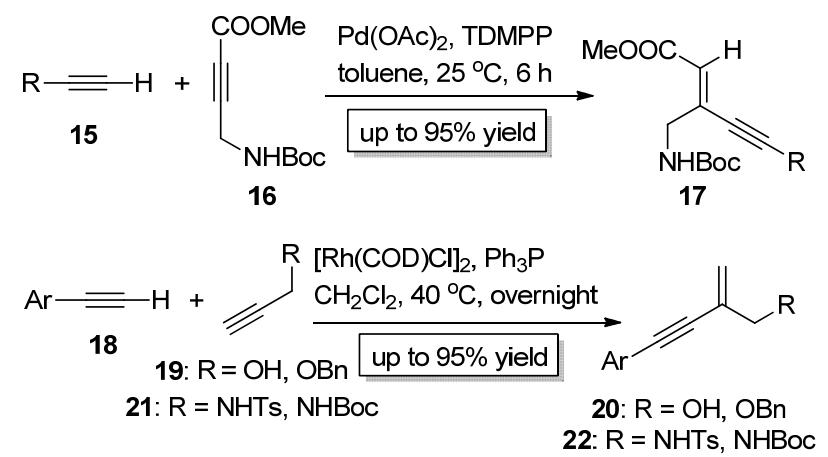

图式 5 钯或铑催化 $\mathrm{C}-\mathrm{H}$ 键对炔键的分子间加成

Scheme $5 \mathrm{Pd}$ or Rh-catalyzed intermolecular addition of $\mathrm{C}-\mathrm{H}$ bond to alkynes

2014 年, $\mathrm{Zhu}$ 等 ${ }^{[9]}$ 报道了 $\mathrm{Pd}_{2}(\mathrm{dba})_{3}$ 催化的炔 23 中的 $\mathrm{C}-\mathrm{H}$ 键对炔胺类底物 24 的分子间加成(Scheme 6), 该 反应具有专一的区域选择性，炔基只加成到与氮原子相 连的炔碳上; 该反应的立体化学选择性也非常好，几乎 只得到反式加成产物 25. 2015 年, Reddy 小组 ${ }^{[10]}$ 也报道 了类似的反应，他们以 $\mathrm{Pd}\left(\mathrm{PPh}_{3}\right)_{2} \mathrm{Cl}_{2}$ 为催化剂实现了炔 26 中的 $\mathrm{C}-\mathrm{H}$ 键对炔基苯基醚类底物 27 的分子间加成 (Scheme 6), 并以专一的区域选择性和立体化学选择性 得到了顺式加成产物 28. Zhu 小组和 Reddy 小组 ${ }^{[11]}$ 发展 的方法所合成的产物都是高度官能团化的烯炔类化合 物，很容易发生多种后续的化学转化，是十分有用的有 机合成中间体.

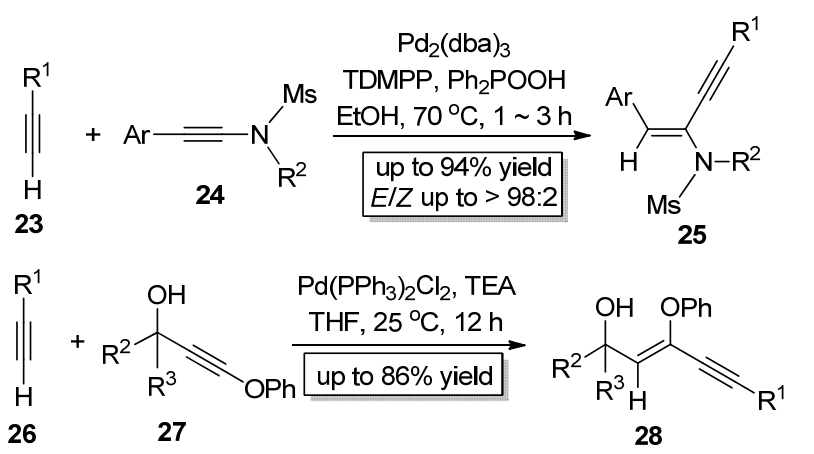

图式 6 钯催化 $\mathrm{C}-\mathrm{H}$ 键对炔键的分子间加成

Scheme 6 Pd-catalyzed intermolecular addition of $\mathrm{C}-\mathrm{H}$ bond to alkynes

\section{$1.2 \mathrm{C}$-B 键对炔键的加成}

2003 年, Suginome 小组 ${ }^{[12]}$ 首次报道了钯或镍催化 的 $\mathrm{C}-\mathrm{B}$ 键对炔键的分子内加成(Scheme 7), 该反应根 据反应底物 29 的不同选取 $\mathrm{Pd}_{2}(\mathrm{dba})_{3}, \mathrm{Pd}\left(\mathrm{PPh}_{3}\right)_{4}$ 或 $\mathrm{Ni}(\mathrm{COD})_{2}$ 为催化剂, 在甲苯中于 $80 \sim 110{ }^{\circ} \mathrm{C}$ 反应 $2 \sim 43$ $\mathrm{h}$ 即可得到目标产物 30. 此反应以极好的区域选择性和 立体化学选择性 $(E: Z=100: 0)$ 以顺式加成的形式得 到 $E$ 式五元环关环产物，该产物可以在不同条件下进一 
步转化为多种重要的有机中间体. 紧接着他们 ${ }^{[13]}$ 又实 现了钯催化的 C-B 键对炔键的分子间加成(Scheme 7), 该反应区域选择性较好, 硼原子主要加成到位阻较小的 炔碳上, 该反应还具有专一的立体化学选择性, 只得到 顺式加成产物. 他们还将此反应运用到了角鲨烯合成酶 抑制剂 P-3622 $2^{[14]}$ 的合成中. 随后, 他们 ${ }^{[15]}$ 于 2006 年以 $\mathrm{Ni}(\mathrm{COD})_{2}$ 为催化剂实现了炔基硼酸酯类底物 35 中的 $\mathrm{C}-\mathrm{B}$ 键对炔键的分子间加成(Scheme 7), 该反应能以高 收率和区域选择性主要得到顺式加成的烯基硼酸酯类 产物 37. Suginome 小组发展的方法为合成官能团化的烯 基硼酸酯类化合物提供了有效的路径.
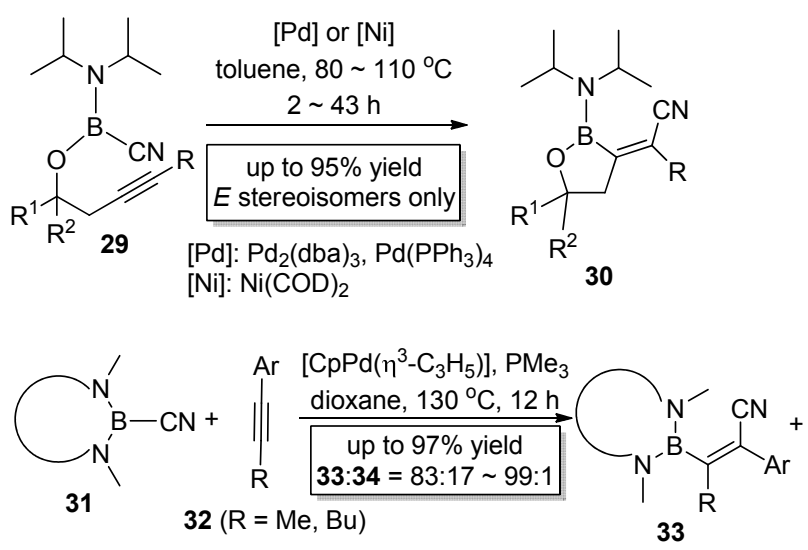<smiles>[R]/C([Al])=C(\[Al])B1N(C)CCCCCN1C</smiles>

33

34
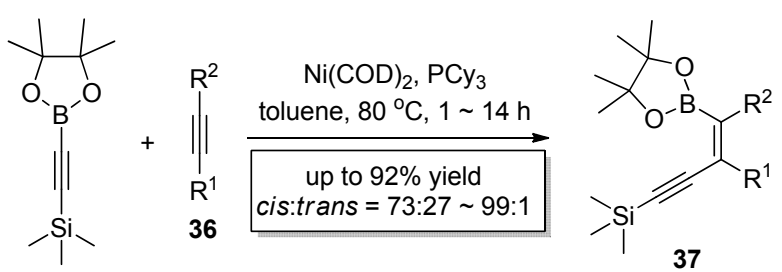

35

图式 7 钯或镍催化 $\mathrm{C}-\mathrm{B}$ 键对炔键的加成

Scheme $7 \mathrm{Pd}$ or Ni-catalyzed addition of $\mathrm{C}-\mathrm{B}$ bond to alkynes

\section{$1.3 \mathrm{C}-\mathrm{N}$ 键对炔键的加成}

$\mathrm{C}-\mathrm{N}$ 键对炔键的加成反应一直是有机化学家们的 研究热点, 因为此类反应可以高效地构建吲哚骨架. 早 期开发的催化体系具有一些缺点, 如催化剂昂贵、反应 收率低等, 然而随着新型催化体系的不断涌现, 这些缺 点都被逐一克服, 这使 $\mathrm{C}-\mathrm{N}$ 键对炔键的加成反应成为 构建高度官能团化的吲哚类化合物的一种重要策略.

2004 年, Yamamoto 课题组 ${ }^{[16]}$ 首次报道了铂催化的 $\mathrm{C}-\mathrm{N}$ 键对炔键的分子内加成(Scheme 8), 他们采用 38 为底物, 以 $\mathrm{PtCl}_{2}$ 为催化剂在苯甲醚中加热至 $80{ }^{\circ} \mathrm{C}$ 即可 得到 $\mathrm{C}-\mathrm{N}$ 键对炔键的分子内加成产物 39, 该反应在
$\mathrm{C}-\mathrm{N}$ 键对炔键进行加成的同时伴随着酰基的分子内 1,3-迁移. 但该方法存在两个不足之处：一是催化剂 $\mathrm{PtCl}_{2}$ 十分昂贵; 二是副产物较多. 大部分底物 38 参与 反应时除了得到目标产物 39 外，还会得到脱酰基副产 物 40 , 而且部分实例中 40 的含量高达 $30 \%$, 这两个缺 点从一定程度上降低了此反应的实用价值. Nakamura 课 题组 ${ }^{[17]}$ 于 2009 年进一步研究了 Yamamoto 发展的催化 体系并拓展了该反应的适用范围(Scheme 8), 他们以 $\mathrm{PtI}_{4}$ 为催化剂实现了底物 41 中的酰胺基的分子内 1,3迁移, 合成了吲哚-3-酰胺类化合物 42, 该反应仍然伴随 着一定比例的脱酰胺基副产物 43; 当使用 $\mathrm{PtCl}_{2}$ 或 $\mathrm{PtCl}_{4}$ 为催化剂时, 可以高效地实现底物 44 结构中的酯基的分 子内 1,3-迁移, 得到吲哚-3-羧酸酯类化合物 $\mathbf{4 5}$, 有趣的 是，该反应中并未检测到脱酯基副产物 46 (Scheme 8).
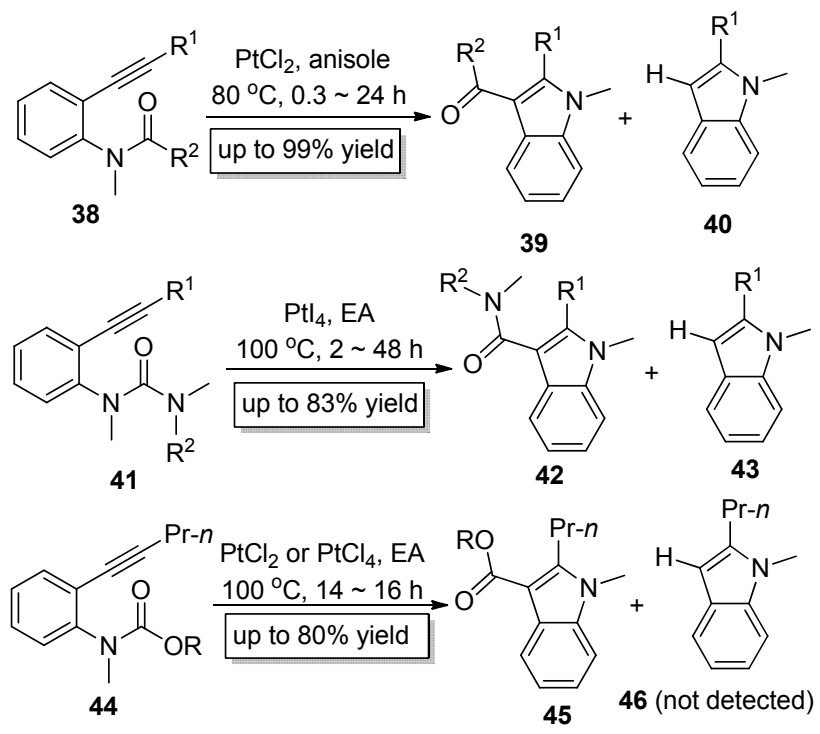

图式 8 铂催化 $\mathrm{C}-\mathrm{N}$ 键对炔键的分子内加成

Scheme 8 Pt-catalyzed intramolecular addition of $\mathrm{C}-\mathrm{N}$ bond to alkynes

$\mathrm{Li}$ 课题组 ${ }^{[18]}$ 于 2012 年报道了钉催化的底物 47 中的 $\mathrm{C}-\mathrm{N}$ 键对炔键的分子内加成(Scheme 9), 该反应能高 效地构建吲哚-3-甲醛类化合物 48. 但该反应时间较长, 且底物适用范围较窄，迁移基团仅限于位阻较小的甲酰 基，位阻稍大的迁移基团如乙酰基等参与反应时收率 低, 这可能是由于钉催化剂的催化活性较低而引起的. 我们课题组 ${ }^{[19]}$ 于 2014 年报道了钯催化的 $\mathrm{C}-\mathrm{N}$ 键对炔 键的加成, 采用 49 为底物, 以 $\mathrm{PdCl}_{2}\left(\mathrm{CH}_{3} \mathrm{CN}\right)_{2}$ 为催化剂 即可快速而高效地构建高度官能团化的吲哚类化合物 50 (Scheme 9). 该反应的迁移基团不但适用于位阻较小 的甲酰基，也适用于位阻较大的乙酰基、丙酰基、异丁 酰基、特戊酰基、苯甲酰基、苯乙酰基等. 此外, 酰胺 基、酮酰基均可以作为迁移基团参与此反应，值得一提 
的是，酮酰基是被首次证明可以作为迁移基团参与此类 反应. 紧接着, 我们 ${ }^{[20]}$ 进一步设计了酮酰胺类底物 51 , 并研究了酮酰胺中的 $\mathrm{C}-\mathrm{N}$ 键对炔键的加成, 此反应能 以高收率得到吲哚-3-酮酰基类化合物 52 (Scheme 9), 为吲哚-3-酮酰基类化合物的制备提供了新方法.
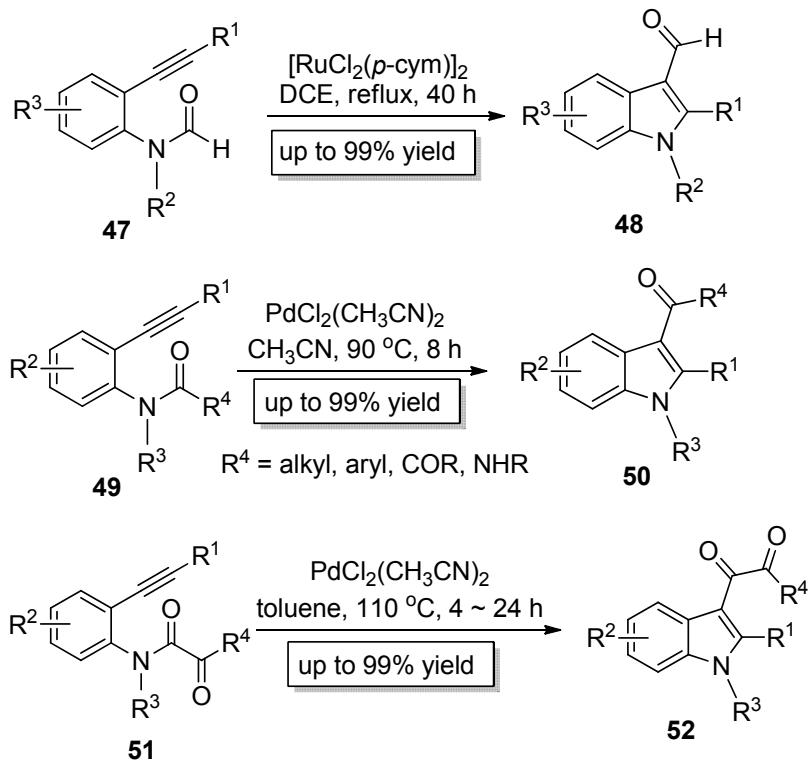

图式 9 钉或钯催化 $\mathrm{C}-\mathrm{N}$ 键对炔键的分子内加成

Scheme $9 \mathrm{Ru}$ or Pd-catalyzed intramolecular addition of $\mathrm{C}-\mathrm{N}$ bond to alkynes

Scheme 10 为以上铂、钟、钯催化的 $\mathrm{C}-\mathrm{N}$ 键对炔 键的加成反应可能的反应机理, 金属催化剂 $[\mathrm{M}]$ 首先与 底物 53 结构中的炔键配合并活化炔键从而生成中间体 A2, 紧接着氮原子对炔键进行亲核进攻生成中间体 B2,

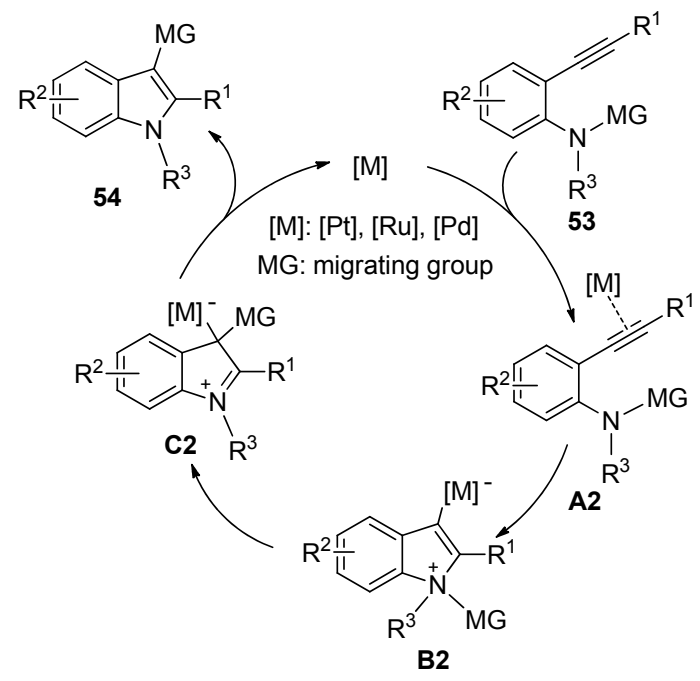

图式 10 铂、钉、钯催化 $\mathrm{C}-\mathrm{N}$ 键对炔键的分子内加成反应 机理

Scheme 10 Proposed reaction mechanism of $\mathrm{Pt}, \mathrm{Ru}$, $\mathrm{Pd}$-catalyzed intramolecular addition of $\mathrm{C}-\mathrm{N}$ bond to alkynes
然后迁移基团 $(\mathrm{MG})$ 发生分子内 1,3-迁移形成中间体 $\mathbf{C 2}$, 最后再消除催化剂得到产物 $\mathbf{5 4}$, 催化剂再进入下一轮 催化循环

基于之前的工作基础，我们课题组 ${ }^{[21]}$ 进一步设计 了 $N$-烯丙基取代的磺酰胺类底物 $\mathbf{5 5}$, 并使用不同价态 的金属钯实现了 $\mathrm{C}-\mathrm{N}$ 键和 $\mathrm{S}-\mathrm{N}$ 键对炔键的选择性加 成(Scheme 11). 当以 $\operatorname{Pd}\left(\mathrm{PPh}_{3}\right)_{4}$ 为催化剂时, 高选择性地 实现 $\mathrm{C}-\mathrm{N}$ 键对炔键的加成，此时烯丙基作为迁移基团 发生分子内 1,3 -迁移; 当以 $\mathrm{PdCl}_{2}\left(\mathrm{CH}_{3} \mathrm{CN}\right)_{2}$ 为催化剂时, 高选择性地实现 $\mathrm{S}-\mathrm{N}$ 键对炔键的加成, 此时磺酰基作 为迁移基团发生分子内 1,3 -迁移. 因此，我们通过同一 种底物 55 成功构建了 1-磺酰基-3-烯丙基吲哚(56)和 1烯丙基-3-磺酰基吲哚(57)这两种吲哚骨架的化合物. 值 得注意的是, 实现 $\mathrm{C}-\mathrm{N}$ 键和 $\mathrm{S}-\mathrm{N}$ 键对炔键的选择性 加成的两种催化体系除了钯催化剂不同之外，其他反应 条件如溶剂、温度等均相同. 之所以仅通过改变钯催化 剂就能实现 $\mathrm{C}-\mathrm{N}$ 键和 $\mathrm{S}-\mathrm{N}$ 键对炔键的选择性加成, 这可能是由 $\mathrm{Pd}\left(\mathrm{PPh}_{3}\right)_{4}$ 和 $\mathrm{PdCl}_{2}\left(\mathrm{CH}_{3} \mathrm{CN}\right)_{2}$ 这两种不同价 态的催化剂因不同的催化机理而导致的截然不同的反 应路径所决定的 $\left(\right.$ Scheme 12). 零价钯 $\mathrm{Pd}\left(\mathrm{PPh}_{3}\right)_{4}$ 首先对 $\mathrm{C}-\mathrm{N}$ 键进行氧化加成生成中间体 $\mathbf{A} 3$, 紧接着在钯的作 用下生成离子对中间体 B3, 然后氮原子对钯活化的炔 键进行亲核加成生成中间体 $\mathbf{C 3}$, 最后还原消除催化剂 而得到产物 56, 释放出的钯催化剂再进入下一轮催化 循环. 二价钯 $\mathrm{PdCl}_{2}\left(\mathrm{CH}_{3} \mathrm{CN}\right)_{2}$ 首先与底物 55 结构中的炔 键配合并活化炔键从而生成中间体 $\mathrm{A4}$, 紧接着氮原子 对炔键进行亲核进攻生成中间体 B4, 然后磺酰基发生 分子内 1,3-迁移形成中间体 C4, 最后再消除催化剂得到 产物 57, 催化剂再进入下一轮催化循环. 此方法既符合 当代多样性合成的要求，也为构建高度官能团化的吲

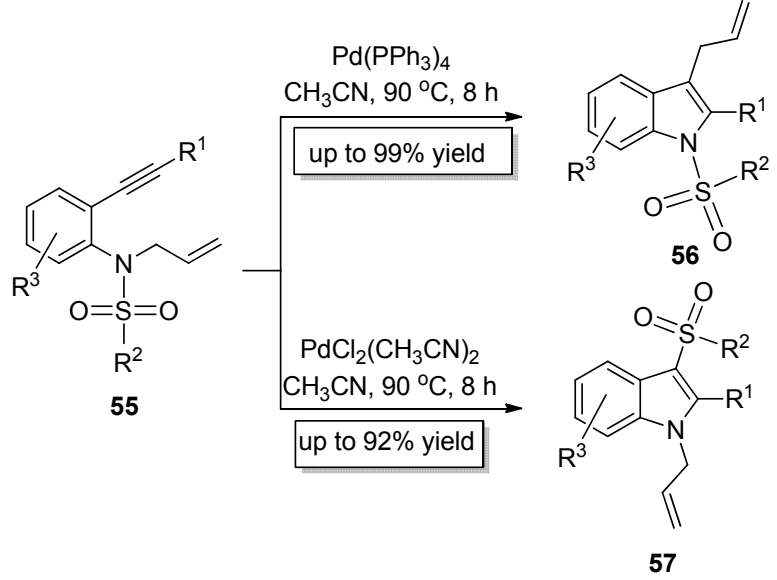

图式 11 钯催化 $\mathrm{C}-\mathrm{N}$ 键和 $\mathrm{S}-\mathrm{N}$ 键对炔键的选择性分子内加 成

Scheme 11 Pd-catalyzed selective intramolecular addition of $\mathrm{C}-\mathrm{N}$ and $\mathrm{S}-\mathrm{N}$ bonds to alkynes 

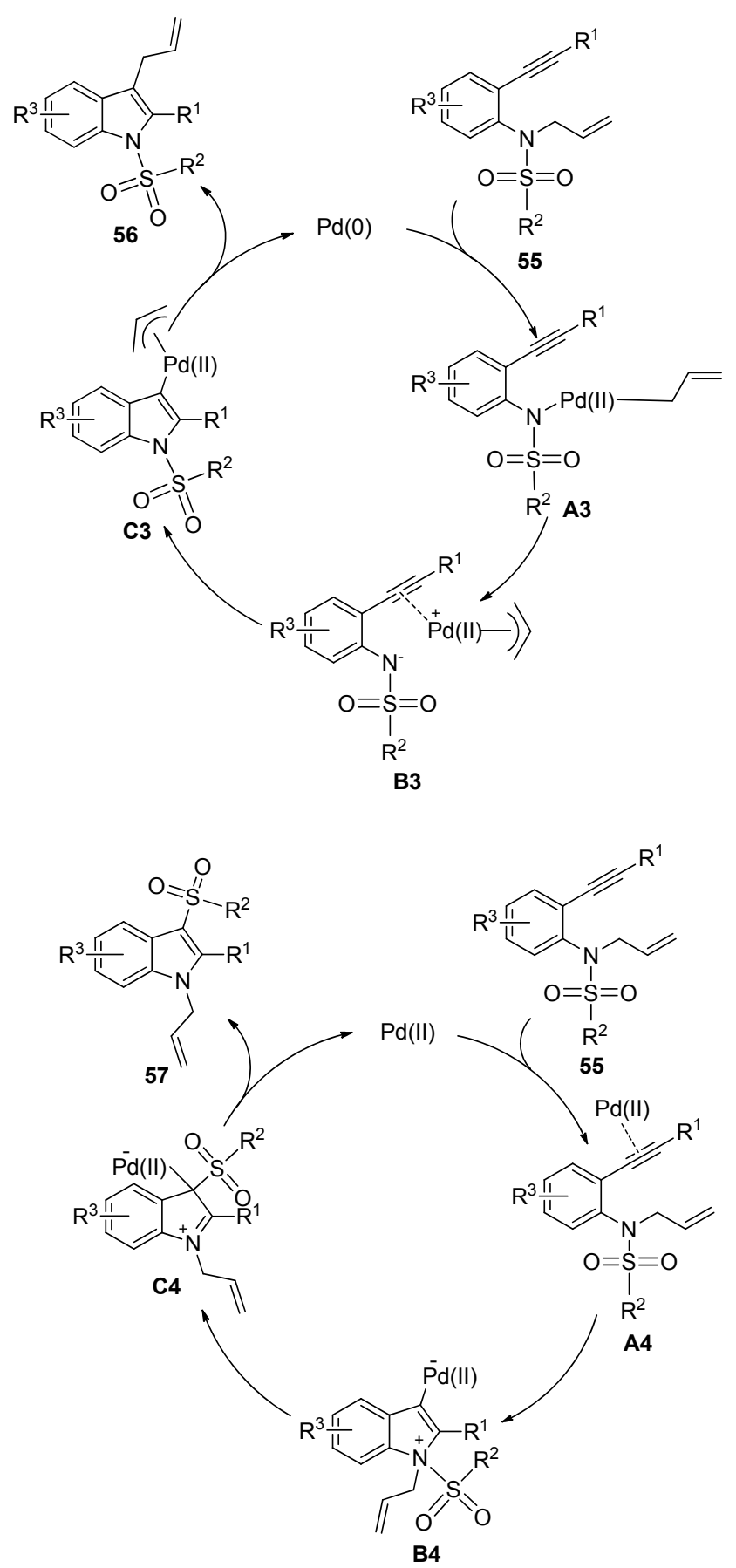

图式 12 零价钯和二价钯分别催化的 $\mathrm{C}-\mathrm{N}$ 键和 $\mathrm{S}-\mathrm{N}$ 键对炔 键的加成反应机理

Scheme 12 Proposed reaction mechanisms of $\mathrm{Pd}(0)$-catalyzed intramolecular addition of $\mathrm{C}-\mathrm{N}$ bond to alkynes and $\mathrm{Pd}(\mathrm{II})$-catalyzed intramolecular addition of $\mathrm{S}-\mathrm{N}$ bond to alkynes 哚类化合物提供了新路径.

2002 年, Yamamoto 等 ${ }^{[22]}$ 以 $\mathrm{Pd}\left(\mathrm{PPh}_{3}\right)_{4}$ 为催化剂实现 了烯丙基苯胺类底物 58 中的 $\mathrm{C}-\mathrm{N}$ 键对炔键的分子内 加成(Scheme 13), 在该反应中, 烯丙基作为迁移基团发 生分子内 1,3-迁移, 从而构建了 3 位烯丙基取代的吲哚 类化合物 59. Roy 小组 ${ }^{[23]}$ 于 2011 年也报道了类似的反
应, 他们以 60 为底物, $\mathrm{AuCl}_{3}$ 为催化剂合成了结构更加 复杂的吲哚类衍生物 61 (Scheme 13). 值得一提的是, Stevens 等 ${ }^{[24]}$ 也以 $\mathrm{AuCl}_{3}$ 为催化剂实现了底物 62 中的 $\mathrm{C}-\mathrm{N}$ 键对炔键的分子内加成(Scheme 13), 该反应伴随 着烯丙基的重排和芳构化反应，构建了 1-氰基取代的异 吲哚类化合物 63.

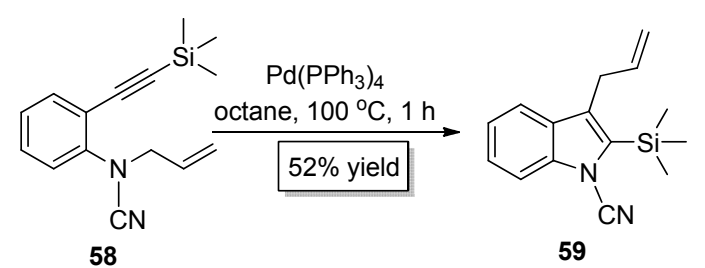

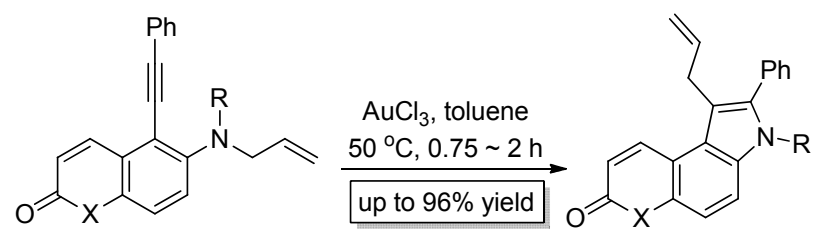

$60(X=O, N M e, N E t)$

61

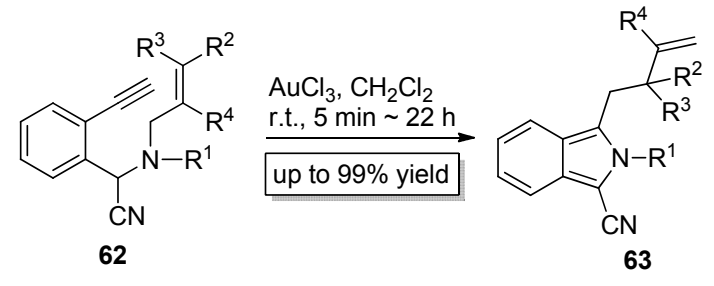

图式 13 钯或金催化 $\mathrm{C}-\mathrm{N}$ 键对炔键的分子内加成 Scheme 13 Pd or Au-catalyzed intramolecular addition of $\mathrm{C}-$ $\mathrm{N}$ bond to alkynes

2007 年, Nakamura 小组 ${ }^{[25]}$ 报道了 $\mathrm{PdBr}_{2}$ 催化的 $\mathrm{C}-$ $\mathrm{N}$ 键对炔键的分子内加成(Scheme 14), 尽管反应产率较 低, 但是烷氧烷基在该反应中作为迁移基团成功地实现 了分子内 1.3-迁移，这进一步增加了迁移基团的种类， 也扩大了 $\mathrm{C}-\mathrm{N}$ 键对炔键的加成反应的适用范围. 2010 年, Bertrand 小组 ${ }^{[26]}$ 以 $\mathrm{AuCl}(\mathrm{CAAC})$ 为催化剂实现了苯 胺类底物 66 中的 $\mathrm{C}-\mathrm{N}$ 键对炔键的加成, 成功地实现了 甲基的分子内 1,3-迁移, 以较高的产率构建了 1,2,3-三 烃基取代的吲哚类化合物 67 (Scheme 14). Pozharskii 小 组 ${ }^{[27]}$ 于 2015 年也报道了类似的反应, 以 $\mathrm{Pd}_{2} \mathrm{dba}_{3}$ 为催化 剂实现了底物 68 中的 $\mathrm{C}-\mathrm{N}$ 键对炔键的分子内加成, 从 而构建了苯并 $[g]$ 吲哚类化合物 69 (Scheme 14). Bertrand 和 Pozharskii 等报道的反应的最大特点是实现了甲基的 分子内 1,3-迁移，而以往同类型反应的迁移基团都是酰 基、酯基、酰胺基、酮酰基等官能团，这也是为数不多 的能实现甲基迁移的加成反应 ${ }^{[28]}$. 


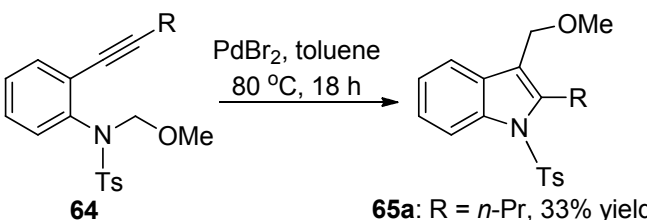

65a: $\mathrm{R}=n-\operatorname{Pr}, 33 \%$ yield 65b: $\mathrm{R}=\mathrm{Ph}, 33 \%$ yield
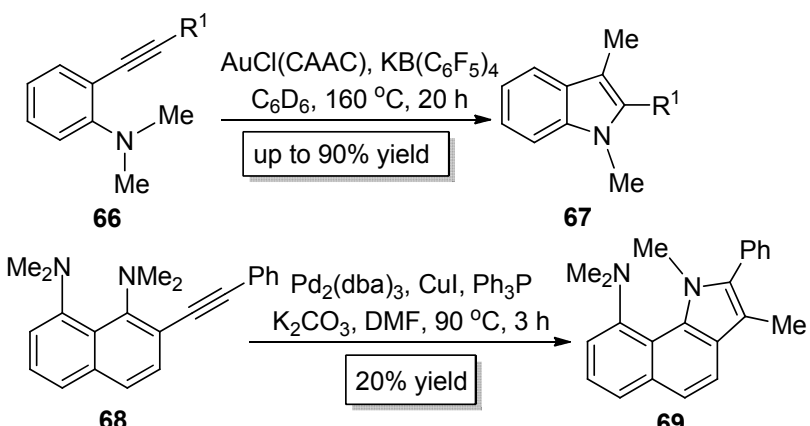

68

69

图式 14 钯或金催化 $\mathrm{C}-\mathrm{N}$ 键对炔键的分子内加成

Scheme 14 Pd or Au-catalyzed intramolecular addition of $\mathrm{C}-$ $\mathrm{N}$ bond to alkynes

\section{$1.4 \mathrm{C}$ - $\mathrm{O}$ 键对炔键的加成}

1998 年, Cacchi 等 ${ }^{[29]}$ 以 70 为底物, $\mathrm{Pd}\left(\mathrm{PPh}_{3}\right)_{4}$ 为催化 剂实现了 $\mathrm{C}-\mathrm{O}$ 键对炔键的分子内加成, 成功合成了苯 并呋喃类化合物 71 和 72 (Scheme 15), 但该反应缺乏选 择性, 大多数情况下得到 71 和 72 的混合物, 而且产率 较低，这些缺点都限制了此反应的实际应用. 2005 年, Yamamoto 小组 ${ }^{[30]}$ 设计了缩醛类底物 73, 并以 $\mathrm{PtCl}_{2}$ 为催

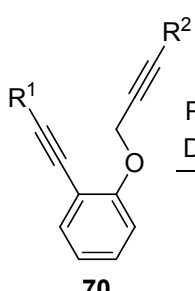

70<smiles>[R]C#Cc1ccccc1OC([R])O[R]</smiles>

73<smiles>[R]C#Cc1ccccc1OC[R]</smiles>

75<smiles>O=C(OCCBr)c1ccccc1C#CC1CC1</smiles>
$\underset{77 \% \text { yield }}{\stackrel{\mathrm{PtCl}_{2}, \mathrm{CO}}{\text { toluene, } 80^{\circ} \mathrm{C}}}$

$\mathrm{PtCl}_{2}, \mathrm{CO}$<smiles>[R]Cc1c([R])oc2ccccc12</smiles>

76

图式 15 钯或铂催化 $\mathrm{C}-\mathrm{O}$ 键对炔键的分子内加成

Scheme 15 Pd or Pt-catalyzed intramolecular addition of $\mathrm{C}-\mathrm{O}$ bond to alkynes
化剂实现了其结构中的 $\mathrm{C}-\mathrm{O}$ 键对炔键加成，以高收率 构建了 3-烷氧烷基取代的苯并呋喃类化合物 74 (Scheme 15). Fürstner 小组 ${ }^{[31]}$ 同时独立报道了与 Yamamoto 小组类似的工作，他们也以 $\mathrm{PtCl}_{2}$ 为催化剂实 现了底物 75 中的 $\mathrm{C}-\mathrm{O}$ 键对炔键加成, 但 Fürstner 等发 展的催化体系底物适用范围更广，底物 75 不仅可以是 缩醛，还可以是苯基烷基醚、苯基烯丙基醚和苯基苄基 醚，这些底物都可以高效地参与反应而得到相应的苯并 呋喃类产物 76 (Scheme 15). 值得一提的是, Fürstner 等 还运用其开发的催化体系以 77 为底物成功构建了含有 异香豆素骨架的产物 78 (Scheme 15). 有趣的是, Yamamoto 小组和 Fürstner 小组在《美国化学学会会刊》 上以 “背靠背” 的形式相继发表了他们的工作. 此外, 麻生明课题组 ${ }^{[32]}$ 于 2007 年报道了钯催化的 $\mathrm{C}-\mathrm{O}$ 键对 炔键的分子内加成(Scheme 16), 他们以 79 和 82 为底物 分别合成了苯并呋喃衍生物 80 和 83 , 尽管此反应伴随 着脱烯丙基副产物(81 或 84), 但此方法为构建复杂的苯 并呋喃类衍生物提供了新的研究思路.
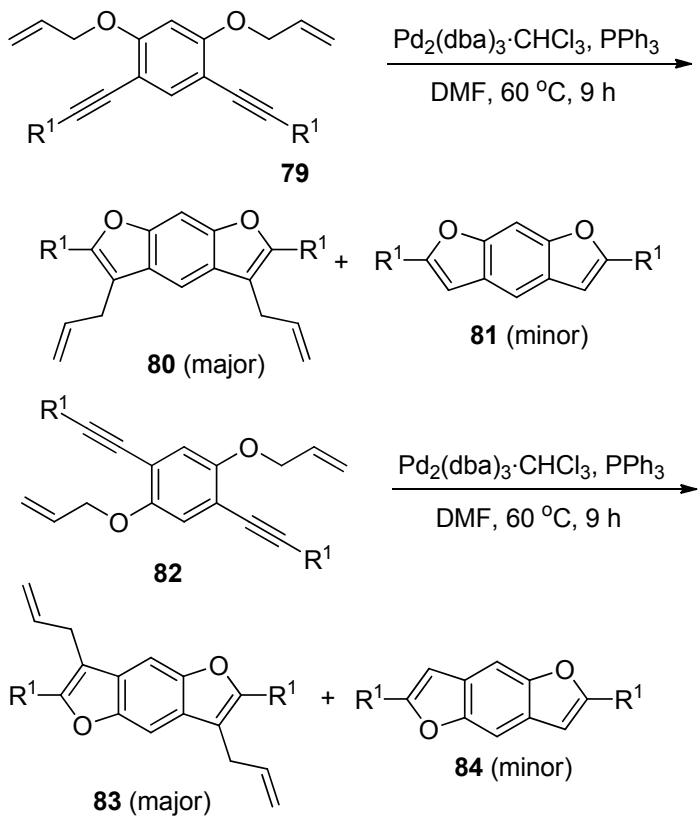

图式 16 钯催化 $\mathrm{C}-\mathrm{O}$ 键对炔键的分子内加成 Scheme 16 Pd-catalyzed intramolecular addition of $\mathrm{C}-\mathrm{O}$ bond to alkynes

2006 年, Toste 小组 ${ }^{[33]}$ 报道了金催化的苄醚类底物 85 中的 $\mathrm{C}-\mathrm{O}$ 键对炔键的分子内加成(Scheme 17), 在该 反应中，甲氧基作为迁移基团发生了分子内 1,3-迁移， 以高收率获得了狮类化合物 86. 有趣的是，当使用缩酮 类底物 87 时，该反应得到的是甲基迁移而非甲氧基迁 移的多取代狮类产物 88 (Scheme 17), 这可能是因为该 反应经历了碳正离子中间体的缘故. 此外, 当使用链状 
化合物 89 为底物时, 反应仍可顺利发生, 从而构建多取 代的环己烯类产物 90 (Scheme 17). 值得一提的是, 手 性底物 $91(99 \% e e)$ 参与反应后, 可以 $92 \%$ 的产率得到手 性产物 $92(95 \% e e)$, 该反应的手性可以得到保持 (Scheme 17).
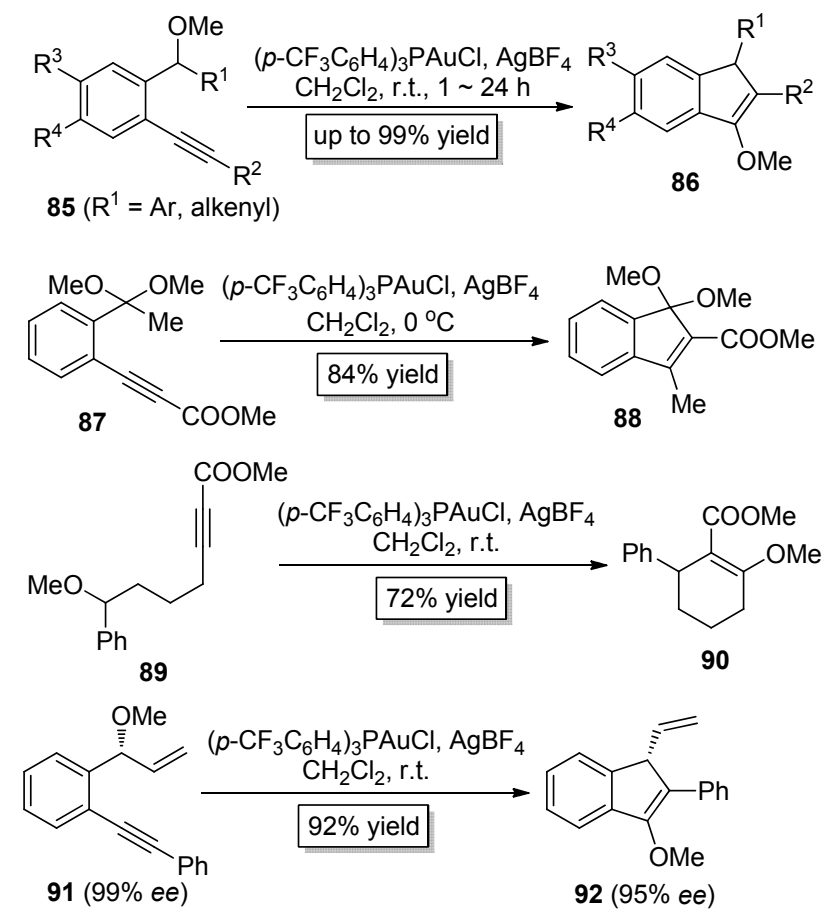

图式 17 金催化 $\mathrm{C}-\mathrm{O}$ 键对炔键的分子内加成

Scheme 17 Au-catalyzed intramolecular addition of $\mathrm{C}-\mathrm{O}$ bond to alkynes

2008 年, Nakamura 小组 ${ }^{[34]}$ 以 $\mathrm{PtCl}_{2}$ 为催化剂实现了 缩醛类底物 93 中的 $\mathrm{C}-\mathrm{O}$ 键对炔键的分子内加成 (Scheme 18), 该反应具有专一的区域选择性, 只以 5-exo 关环的方式得到五元环产物. 有趣的是, 该反应 的立体化学选择性受酯基上的 $\mathrm{R}^{1}$ 取代基的影响较大, 当 $\mathrm{R}^{1}$ 为 $2,2,2$-三氯乙基时，反应主要以反式加成的方式
得到 $Z$ 式产物; 当 $\mathrm{R}^{1}$ 为苯基时，反应主要以顺式加成的 方式得到 $E$ 式产物 ${ }^{[35]}$. 此外, 他们在后续的研究中还进 一步发现该反应使用的配体对立体化学选择性也存在

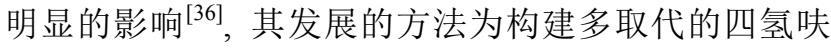
喃类衍生物提供了有力工具.

Takaki 等 ${ }^{[37]}$ 于 2008 年以 $\mathrm{Bi}(\mathrm{OTf})_{3}$ 为催化剂实现了 炔酸酯类底物 98 中的 $\mathrm{C}-\mathrm{O}$ 键对炔键的分子内加成 (Scheme 19), 该反应主要以 6-endo 关环的方式得到反 式加成的六元内酯类产物 99. Blum 小组 ${ }^{[38]}$ 也报道了邻 炔基苯甲酸烯丙基酯类底物 $\mathbf{1 0 0}$ 中的 $\mathrm{C}-\mathrm{O}$ 键对炔键的 分子内加成反应, 该反应在 $\mathrm{PPh}_{3} \mathrm{AuCl}$ 和 $\mathrm{Pd}_{2}(\mathrm{dba})_{3}$ 的共 同催化下，能以高收率获得异香豆素骨架的产物 101 (Scheme 19). 此外, Miyata 课题组 ${ }^{[39]}$ 于 2010 年报道了肟 醚类底物 102 中的 $\mathrm{C}-\mathrm{O}$ 键对炔键的分子内加成反应, 该反应以 $\mathrm{AuCl}_{3}$ 为催化剂, 以 $1,2-$ 二氯乙烷为溶剂, 回 流 $2 \mathrm{~h}$ 即可高收率地得到多取代的异噁唑类化合物 103 (Scheme 19). 2016 年, Mino 小组 ${ }^{[40]}$ 报道了苯基烯丙基醚 类底物 104 结构中的 $\mathrm{C}-\mathrm{O}$ 键对炔键的分子内加成 (Scheme 19), 该反应以 $\operatorname{Pd}_{2}(\mathrm{dba})_{3}$ 为催化剂在含水溶剂 体系中即可构建多取代的苯并呋喃类化合物 105. 由此 可见，金属催化的 $\mathrm{C}-\mathrm{O}$ 键对炔键的加成反应可以高效 而快速地构建含氧的结构丰富多样的有机杂环类化合 物 $^{[41]}$, 具有重要的应用价值.

\section{$1.5 \mathrm{C}-\mathrm{Si}$ 键对炔键的加成}

Jung 小组 ${ }^{[42]}$ 于 1995 年以 $\mathrm{AlCl}_{3}$ 为催化剂实现了烯 丙基三甲基硅烷 106 中的 $\mathrm{C}-\mathrm{Si}$ 键对苯炔 107 的分子间 加成，该反应具有很好的立体化学选择性和区域选择 性. 当使用的苯炔 107 中的 $\mathrm{R}$ 取代基为位阻较小的基团 如氢、甲基时，三甲基硅基主要加成到位阻较小的炔碳 上，烯丙基主要加成到位阻较大的炔碳上，而且以顺式 加成的方式得到 $E$ 式产物(Scheme 20); 当使用的苯炔为 位阻较大的对称的二苯基乙炔 110 时，反应主要以反式

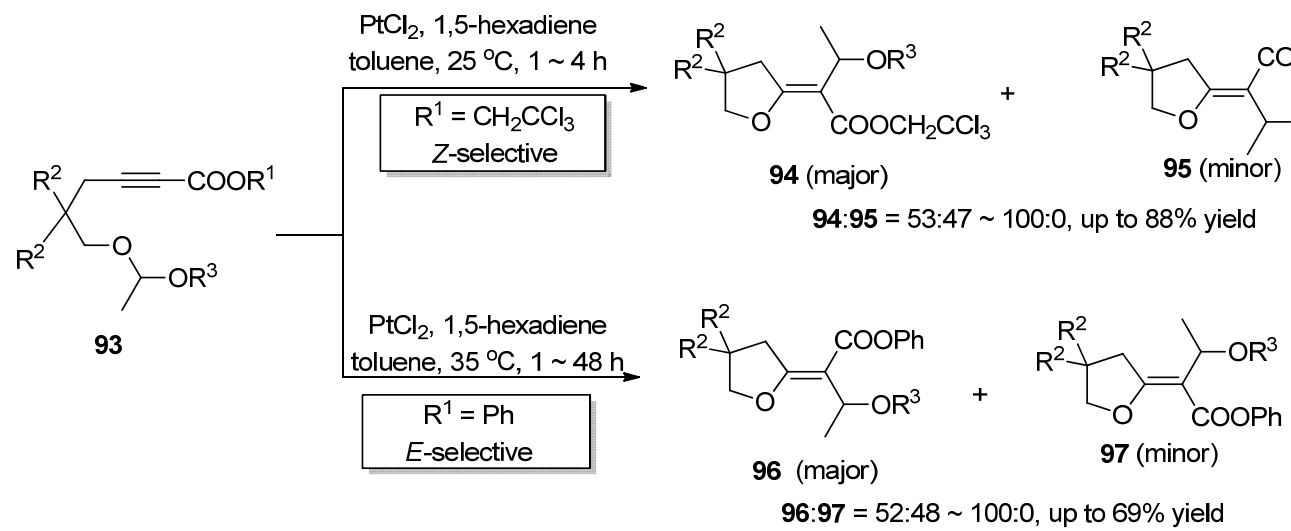

图式 18 铂催化 $\mathrm{C}-\mathrm{O}$ 键对炔键的分子内加成

Scheme 18 Pt-catalyzed intramolecular addition of $\mathrm{C}-\mathrm{O}$ bond to alkynes 
<smiles>[R]C#CCC(C)(C)C(=O)OC([R])[R]</smiles>

$\mathrm{Bi}(\mathrm{OTf})_{3}, \mathrm{DCE}$

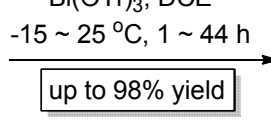

98<smiles>[R]C#Cc1ccccc1C(=O)OCC=C</smiles>

100

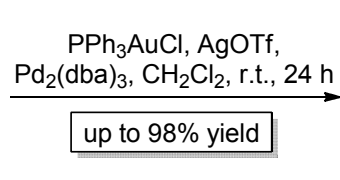

99

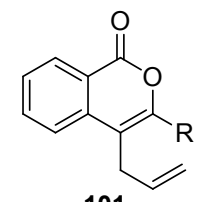

101

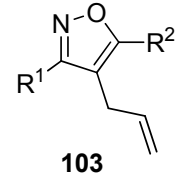

103
102
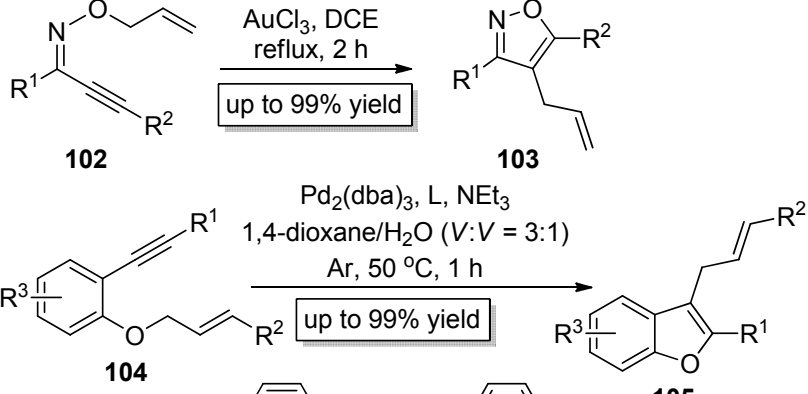

104<smiles>CN(/N=C/C=N/N(C)c1ccccn1)c1ccccn1</smiles>

105

图式 19 铋、金、钯催化 $\mathrm{C}-\mathrm{O}$ 键对炔键的分子内加成

Scheme $19 \mathrm{Bi}, \mathrm{Au}$, Pd-catalyzed intramolecular addition of $\mathrm{C}-$ $\mathrm{O}$ bond to alkynes

加成的方式得到 $Z$ 式产物 111 (Scheme 20). 尽管该反应 产率中等, 但属首次实现烯丙基和硅基对炔键的加成. 紧接着, Yamamoto 小组 ${ }^{[33,44]}$ 以 $\mathrm{EtAlCl}_{2}$ 为催化剂实现了 类似的反应(Scheme 20), 该反应与 Jung 小组报道的反 应具有相同的区域选择性, 但该反应只得到反式加成产 物, 而且反应产率大幅度提高, 这使得该类反应更加实 用和高效, Yamamoto 等 ${ }^{[45]}$ 还将此反应用于有机硅聚合 物的合成中.

$$
\begin{aligned}
& \underset{106}{\mathrm{Si}_{C}^{\prime}}+\mathrm{R} \underset{107}{=} \mathrm{Ph} \frac{\mathrm{AlCl}_{3} \text {, benzene }}{24^{\circ} \mathrm{C}}-\underset{\mathrm{R}}{-\mathrm{Si}_{\mathrm{i}}^{\prime}}=\mathrm{Ph}_{\mathrm{Ph}} \\
& \text { 108a: } R=H, 10 \text { min, 34\% yield } \\
& \text { 108b: } R=\text { Me, } 25 \mathrm{~min}, 66 \% \text { yield }
\end{aligned}
$$

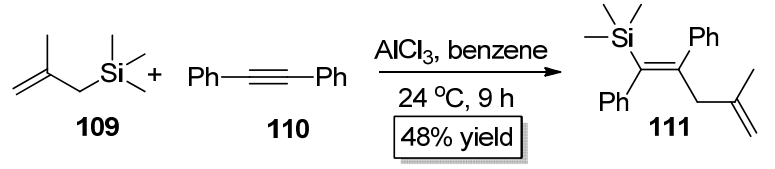

$$
112 \quad 113\left(\mathrm{R}^{2}=\mathrm{H}, \mathrm{Me}\right) \stackrel{-47^{\circ} \mathrm{C}, 2 \mathrm{~h}}{\text { up to } 95 \% \text { yield }}
$$

图式 20 铝催化 $\mathrm{C}-\mathrm{Si}$ 键对炔键的分子间加成

Scheme 20 Al-catalyzed intermolecular addition of $\mathrm{C}-\mathrm{Si}$ bond to alkynes

继实现烯丙基和硅基对炔键的加成之后, Yamamoto 小组 ${ }^{[46,47]}$ 紧接着实现了烯基和硅基对炔键的加成. 当使 用炔键和烯键由碳原子连接的底物 115 时, 以 $\mathrm{EtAlCl}_{2}$ 或 $\mathrm{AlCl}_{3}$ 为催化剂, 反应只以 exo 关环的方式只得到反 式加成产物 116; 当使用炔键和烯键由碳原子连接的底 物 117 时, 以 $\mathrm{EtAlCl}_{2}$ 为催化剂, 反应只以 edo 关环的方 式只得到反式加成产物 118; 当使用炔键和烯键由硅原 子连接的底物 119 时, 以 $\mathrm{EtAlCl}_{2}$ 为催化剂, 反应只以 6-edo 关环的方式只得到反式加成产物 120 (Scheme 21). 随后，他们 ${ }^{[47]}$ 又实现了苯基和硅基对炔键的加成，当使 用苯基和炔基由碳原子相连的底物 121 或 123 时, 分别 以 $\mathrm{HfCl}_{4}$ 或 $\mathrm{EtAlCl}_{2}$ 为催化剂, 反应只以 exo 关环的方式 只分别得到反式加成产物 122 或 124 ; 当使用苯基和

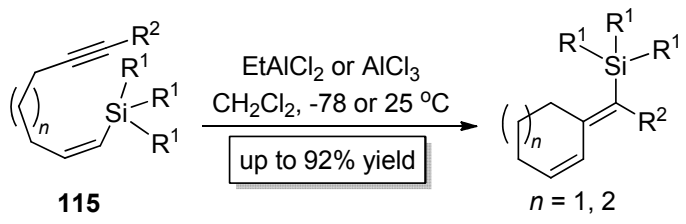

116<smiles>[R7]C=C1C=CC#C[Si]1(C)C</smiles>

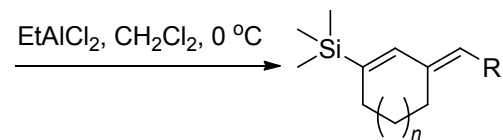

118a: $n=1, \mathrm{R}=\mathrm{C}_{3} \mathrm{H}_{7} ; 90 \%$ yield 118b: $n=2, \mathrm{R}=\mathrm{C}_{3} \mathrm{H}_{7} ; 35 \%$ yield

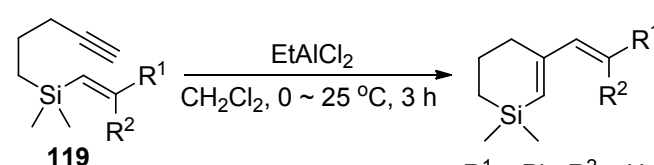

120a: $R^{1}=P h, R^{2}=H ; 92 \%$ yield 120b: $R^{1}=H, R^{2}=$ Me; $83 \%$ yield<smiles>C#CCCCc1ccccc1[Si](C)(C)C</smiles>

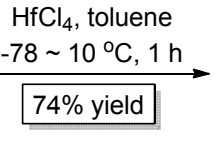<smiles>C[Si](C)(C)/C=C1\CCCc2ccccc21</smiles><smiles>C#CCCCCc1ccccc1[Si](C)(C)C</smiles>

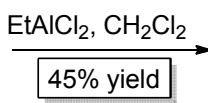<smiles>[R4][Si](C)(C)/C=C1\CCCCc2ccccc21</smiles><smiles>C#CC[Si](C)(C)[Al]</smiles>

125

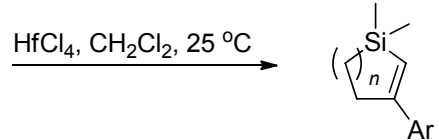

126a: $n=1, \mathrm{Ar}=\mathrm{Ph} ; 71 \%$ yield 126b: $n=1, \mathrm{Ar}=p$-Tolyl; $57 \%$ yield 126c: $n=1, \mathrm{Ar}=0$-Tolyl; $20 \%$ yield 126d: $n=2, \mathrm{Ar}=\mathrm{Ph} ; 15 \%$ yield

图式 21 铝或铪催化 $\mathrm{C}-\mathrm{Si}$ 键对炔键的分子内加成 Scheme 21 Al or Hf-catalyzed intramolecular addition of $\mathrm{C}-$ Si bond to alkynes 
炔基由硅原子相连的底物 $\mathbf{1 2 5}$ 时, 反应只以 edo 关环的 方式只得到反式加成产物 126 (Scheme 21). Yamamoto 小组发展的方法可以便捷地合成常规方法难以得到的 环己烯、环庚烯、苯并环己烷、苯并环庚烷骨架的有机 硅类化合物、硅杂环戊烯和硅杂环己烯类化合物, 具有 重要的研究价值.

2008 年, Murakami 小组 ${ }^{[48}$ 报道了烯丙基硅类化合 物 127 中的 $\mathrm{C}-\mathrm{Si}$ 键对炔键的分子内加成(Scheme 22), 该反应以 $\mathrm{AuNTf}_{2}$ 为催化剂, 在二氯甲烷中于室温反应 2 $\sim 9 \mathrm{~h}$ 即可以较高的产率得到 3 位烯丙基取代的苯并噻 咯(硅茆)类产物 128, 该反应的产率受金催化剂的配体 影响较大, 配体以 2-(二叔丁基膦)联苯为最佳. 此外,

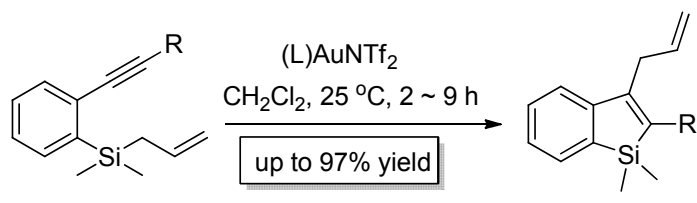

127 $\mathrm{P}(t-\mathrm{Bu})_{2}$ 128 $\mathrm{L}=$

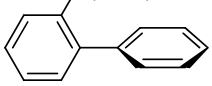

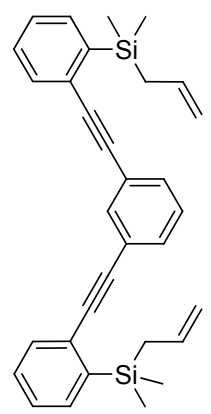

129

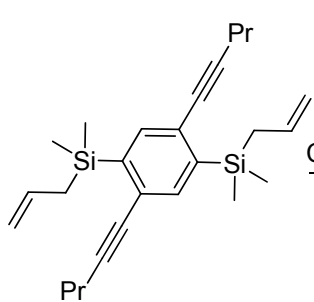

131

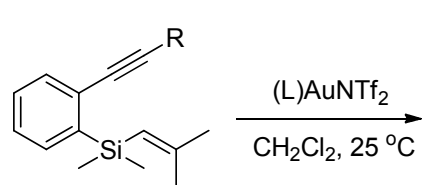

133

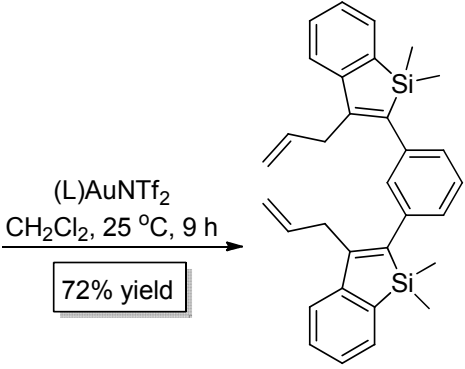

130

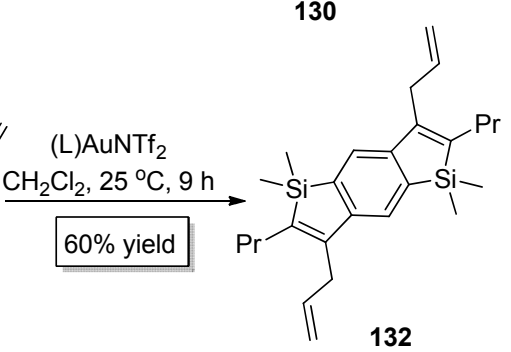

132<smiles>[R]C1=C(C=C(C)C)c2ccccc2[Si]1(C)C</smiles>

134a: $\mathrm{R}=\mathrm{H}, 2 \mathrm{~h}, 73 \%$ yield 134b: $\mathrm{R}=\mathrm{Bu}, 4 \mathrm{~h}, 44 \%$ yield

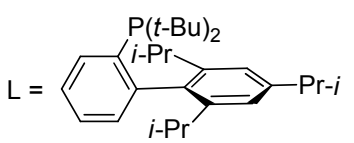

图式 22 金催化 $\mathrm{C}-\mathrm{Si}$ 键对炔键的分子内加成 Scheme 22 Au-catalyzed intramolecular addition of $\mathrm{C}-\mathrm{Si}$ bond to alkynes
当 $(\mathrm{R}=t-\mathrm{Bu})$ 时，反应不发生. 有趣的是，他们还以 129 和底物 127 是末端炔烃 $(R=H)$ 或位阻较大的非末端炔烃 131 为底物分别构建了复杂的二聚苯并噻咯类化合物 130 和 132 (Scheme 22). 紧接着, 他们 ${ }^{[49,50]}$ 又设计了烯 基硅类底物 133, 并实现了其结构中的 $\mathrm{C}-\mathrm{Si}$ 键对炔键 的分子内加成(Scheme 22), 成功构建了 3 位烯基取代的 苯并噻咯类化合物 134, Murakami 等开发的方法为合成 苯并噻咯类化合物提供了新路径 ${ }^{[51]}$.

\section{$1.6 \mathrm{C}-\mathrm{S}$ 键对㶧键的加成}

Yamamoto 小组 ${ }^{[52]}$ 于 2004 年以 $\mathrm{PdI}_{2}$ 为催化剂实现了 硫缩醛类底物 135 中的 $\mathrm{C}-\mathrm{S}$ 键对炔键的分子内加成 (Scheme 23)，以高产率得到了 1,3-双硫代的狮类产物 136. 紧接着他们 ${ }^{[53]}$ 采用 $\mathrm{AuCl}$ 为催化剂实现了底物 137 中的 C-S 键对炔键的分子内加成(Scheme 23), 此反应 仅需使用 $2 \%$ 的 $\mathrm{AuCl}$ 为催化剂, 以二氯甲烷为溶剂在室 温即可发生. 虽然硫原子上的烷基取代基发生了分子内 1,3-迁移，但绝大部分手性底物参与反应后，反应的手 性基本可以得到保持.<smiles>[R]C#Cc1ccccc1C([R1])[R15]</smiles>

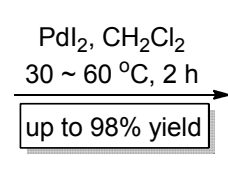

35

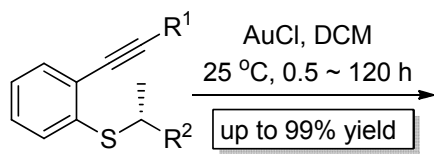

137<smiles>[R1]C1=C([R])C([R18])c2ccccc21</smiles><smiles>[R]c1sc2ccccc2c1C([R])C</smiles>

138
图式 23 钯或金催化 $\mathrm{C}-\mathrm{S}$ 键对炔键的分子内加成 Scheme 23 Pd or Au-catalyzed intramolecular addition of $\mathrm{C}-\mathrm{S}$ bond to alkynes

2005 年, Kambe 小组 ${ }^{[4]}$ 报道了 $\operatorname{Pd}\left(\mathrm{PPh}_{3}\right)_{4}$ 催化的 $\mathrm{C}-\mathrm{S}$ 键对炔键的分子内加成(Scheme 24), 该反应以 139 为底物, 只需要 $5 \%$ 的 $\mathrm{Pd}\left(\mathrm{PPh}_{3}\right)_{4}$ 作为催化剂, 在甲苯中 回流 $1 \mathrm{~h}$ 即可以 $72 \%$ 的产率得到加成产物，该反应具有 专一的区域选择性和立体化学选择性, 只得到 $Z$ 式四元 内酰胺目标产物 140. 2006 年, Ogawa 小组 ${ }^{[55]}$ 也以 $\mathrm{Pd}\left(\mathrm{PPh}_{3}\right)_{4}$ 为催化剂实现了硫氰酸酯 141 中的 $\mathrm{C}-\mathrm{S}$ 键对 端炔 142 的分子间加成(Scheme 24), 该反应具有专一的 区域选择性，氰基只加成到末端炔碳上，该反应还具有 较高的立体化学选择性, 主要得到顺式加成产物 143. 该反应首次成功地将硫原子和氰基分别引入到炔基碳 的两端, 从而构建了高度官能团化的 $\beta$ 位硫取代的 $\alpha, \beta$ 不饱和腈类化合物. 

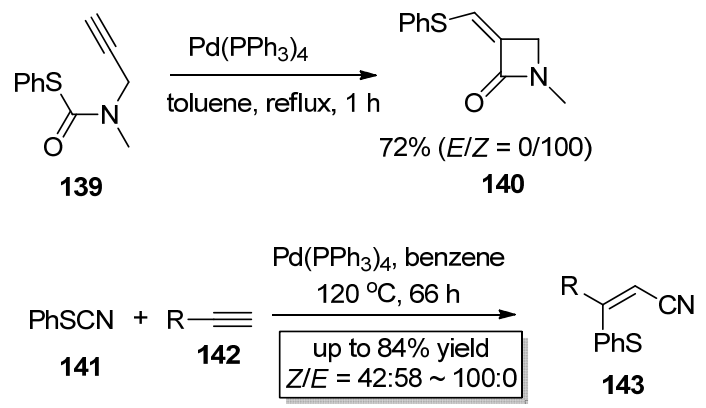

图式 24 钯催化 $\mathrm{C}-\mathrm{S}$ 键对炔键的加成

Scheme 24 Pd-catalyzed addition of $\mathrm{C}-\mathrm{S}$ bond to alkynes

2006 年, Nakamura 课题组 ${ }^{[56]}$ 实现了烷氧烷基苯基 硫醚类底物 144 中的 $\mathrm{C}-\mathrm{S}$ 键对炔键的分子内加成 (Scheme 25), 该反应以 $\mathrm{AuCl}$ 为催化剂, 以甲苯为溶剂 在室温反应 $2 \mathrm{~h}$ 即可高产率得到苯并噻吩产物 145, 在 该反应中, 烷氧烷基作为迁移基团发生了分子内 1,3-迁 移. 值得一提的是, 该反应同样适用于茮基苯基硫醚类 底物 146 和烯丙基苯基硫醚类底物 148 (Scheme 25), Nakamura 小组发展的方法产率高、底物适用范围广, 为 合成官能团化的 2,3-双取代的苯并噻吩类化合物提供了 便捷的方法.
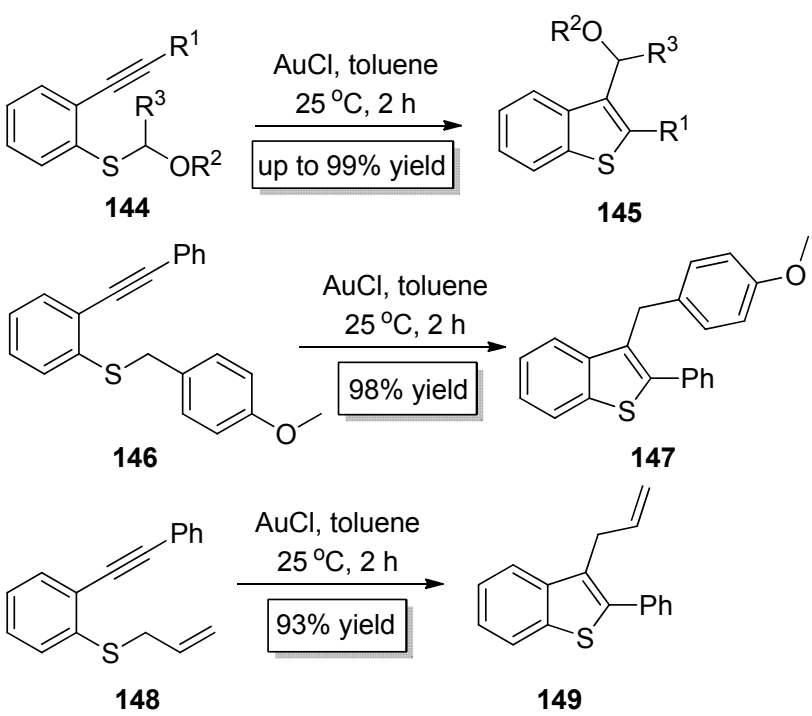

图式 25 金催化 $\mathrm{C}-\mathrm{S}$ 键对炔键的分子内加成 Scheme 25 Au-catalyzed intramolecular addition of $\mathrm{C}-\mathrm{S}$ bond to alkynes

2012 年, Willis 小组 ${ }^{[57]}$ 实现了铑催化的苯基甲基硫 醚 150 中的 $\mathrm{C}-\mathrm{S}$ 键对端炔 151 的分子间加成(Eq. 2), 该 反应具有专一的区域选择性, 硫原子只加成到非末端炔 碳上, 该反应还具有专一的立体化学选择性, 只得到顺 式加成产物 152. 该方法具有选择性好、产率高、底物 适用范围广等特点, 能高效地构建官能团化的烯基硫醚 类化合物 ${ }^{[58]}$.

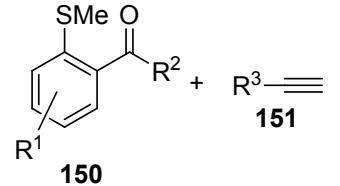

[Rh(DPEphos)(nbd)][BArF 4$]$

$130^{\circ} \mathrm{C}, \mathrm{o}$-xylene, $1 \mathrm{~h}$ or [Rh(DPEphos)(o-xylene)][BArF 4 $60{ }^{\circ} \mathrm{C}$, o-xylene, $4 \sim 24 \mathrm{~h}$

up to $98 \%$ yield<smiles>[R]C(=O)c1ccc([R16])cc1C=C([R3])S([R])([R])([R])([R])C</smiles>

\section{$1.7 \mathrm{C}-\mathrm{X}(\mathrm{X}=\mathrm{Cl}, \mathrm{Br}, \mathrm{I})$ 键对炔键的加成}

\subsection{1 $\mathrm{C}(\mathrm{sp})-\mathrm{Br}$ 键对炔键的加成}

2010 年, Feng 小组 ${ }^{[59]}$ 报道了炔基溴类底物 153 中的 $\mathrm{C}(\mathrm{sp})-\mathrm{Br}$ 键对炔 154 的分子间加成(Scheme 26), 该反 应以 $\mathrm{Pd}(\mathrm{OAc})_{2}$ 为催化剂, 在乙腈中于 $30{ }^{\circ} \mathrm{C}$ 反应 $8 \mathrm{~h}$ 即 可以较高收率得到顺式加成产物 155 , 当使用的是非对 称炔时，反应的区域选择性受炔底物上的取代基影响较 大. 2011 年, Ohe 小组 ${ }^{[60]}$ 报道了 $\mathrm{GaCl}_{3}$ 催化的溴化氰 156 中的 $\mathrm{C}(\mathrm{sp})-\mathrm{Br}$ 键对炔键的分子间加成(Scheme 26), 该 反应区域选择性极好，氧基只加成到位阻较小的炔碳 上，该反应立体化学选择性也非常好，主要以顺式加成 的形式得到 $Z$ 式产物 $158(Z: E>90 ： 10)$. 该反应成功 地在炔基碳的两端分别引入了溴和氰基，从而构建了高 度官能团化的 $\beta$-溴- $\alpha, \beta$-不饱和腈类化合物.

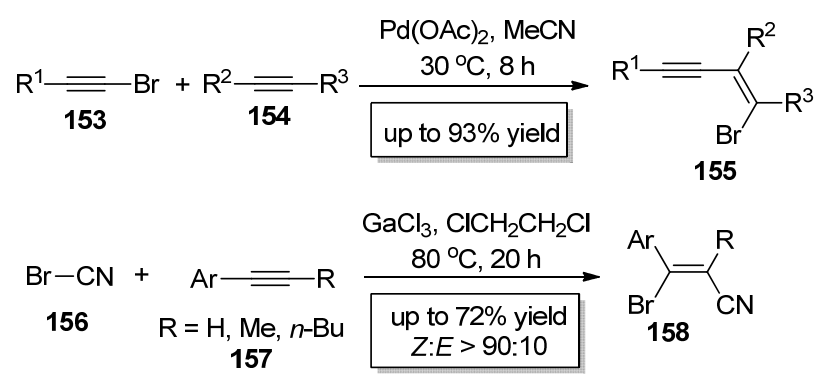

图式 26 钯或镓催化 $\mathrm{C}(\mathrm{sp})-\mathrm{Br}$ 键对炔键的分子间加成 Scheme $26 \mathrm{Pd}$ or Ga-catalyzed intermolecular addition of $\mathrm{C}(\mathrm{sp})-\mathrm{Br}$ bond to alkynes

\subsection{2 $\mathrm{C}\left(\mathrm{sp}^{2}\right)-\mathrm{X}(\mathrm{X}=\mathrm{Cl}, \mathrm{Br}, \mathrm{I})$ 键对炔键的加成}

1998 年, Tanaka 小组 ${ }^{[61]}$ 首次实现了氯甲酸甲酯 $\mathbf{1 5 9}$ 中的 $\mathrm{C}\left(\mathrm{sp}^{2}\right)-\mathrm{Cl}$ 键对端炔 $\mathbf{1 6 0}$ 的分子间加成(Scheme $27)$, 该反应以 $\mathrm{RhCl}(\mathrm{COD})\left(\mathrm{PPh}_{3}\right)$ 为催化剂, 在甲苯中于 $110{ }^{\circ} \mathrm{C}$ 即可顺利进行, 该反应区域选择性极好, 氯原子 只加成到非末端炔碳上; 该反应立体化学选择性也非常 好, 主要以顺式加成的形式得到 $Z$ 式产物 $161(Z: E=$ $94: 6 \sim 100: 0)$. 随后他们 ${ }^{[62]}$ 又报道了 $\mathrm{Rh}(\mathrm{acac})(\mathrm{CO})-$ 
$\left(\mathrm{AsPh}_{3}\right)$ 催化的氯乙酰氯 162 中的 $\mathrm{C}\left(\mathrm{sp}^{2}\right)-\mathrm{Cl}$ 键对端炔 163 的分子间加成(Scheme 27), 以相同的区域选择性主 要得到了顺式加成产物 $164(Z: E=53: 47 \sim 100: 0)$. Tanaka 小组发展的方法可以快速而高效地构建高度官 能团化的 $\beta$-氯 $-\alpha, \beta$-不饱和酯和 $\beta$-氯- $\alpha, \beta$-不饱和酮类化合 物, 具有重要的实用价值.

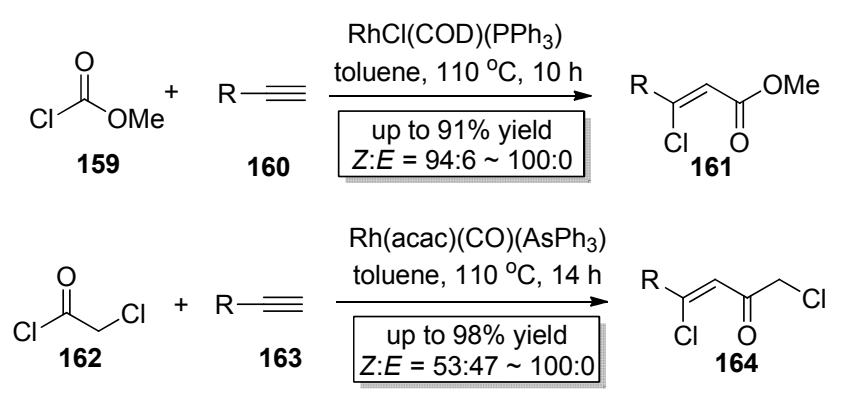

图式 27 铑催化 $\mathrm{C}\left(\mathrm{sp}^{2}\right)-\mathrm{Cl}$ 键对炔键的分子间加成 Scheme 27 Rh-catalyzed intermolecular addition of $\mathrm{C}\left(\mathrm{sp}^{2}\right)-\mathrm{Cl}$ bond to alkynes

2000 年, $\mathrm{Grigg}$ 小组 ${ }^{[63]}$ 以 $\mathrm{Pd}(\mathrm{OAc})_{2}$ 为催化剂实现了 底物 165 中的 $\mathrm{C}\left(\mathrm{sp}^{2}\right)-\mathrm{Cl}$ 键对炔键的加成, 顺式加成产 物不经分离直接与有机锡试剂 166 发生 Stille 偶联, 即 可一锅快速构建吡咯烷酮或氧化吲哚类化合物 167 (Scheme 28). 当该反应以 $\mathbf{1 6 8}$ 为底物时, 可以一锅快速 构建七元内酰胺化合物 $\mathbf{1 7 0}$ (Scheme 28).
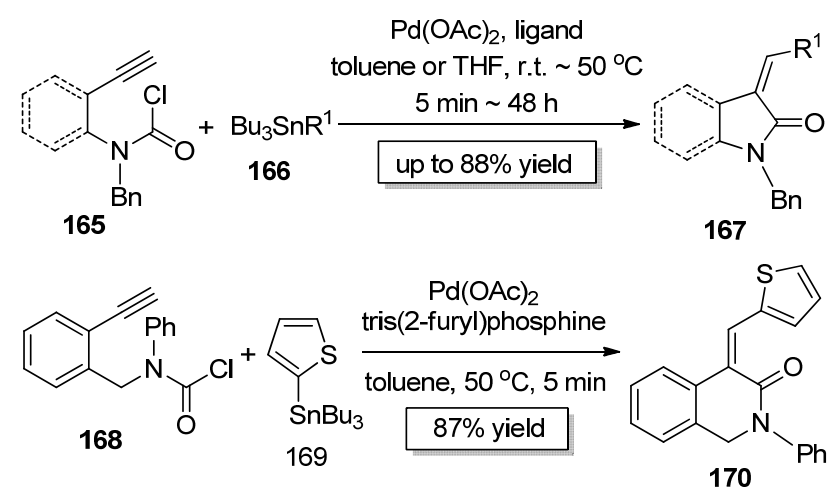

图式 28 钯催化 $\mathrm{C}\left(\mathrm{sp}^{2}\right)-\mathrm{Cl}$ 键对炔键的分子内加成

Scheme 28 Pd-catalyzed intramolecular addition of $\mathrm{C}\left(\mathrm{sp}^{2}\right)-\mathrm{Cl}$ bond to alkynes

2009 年, Tsuji 课题组 ${ }^{[64]}$ 以 $\operatorname{IrCl}(\mathrm{COD})(\mathrm{IPr})$ 为催化剂 实现了酰氯底物 171 中 $\mathrm{C}\left(\mathrm{sp}^{2}\right)-\mathrm{Cl}$ 键对端炔 172 的分子 间加成(Scheme 29). 该反应区域选择性极好, 只选择性 地生成一种区域加成产物, 此反应的立体选择性也非常 好, 几乎只生成顺式加成产物 173. 有趣的是, 当铱催 化剂的配体变成 RuPhos 后, 该反应会释放出一分子一 氧化碳而生成产物 174. 此外, 他们还采用 175 和 176 为反应底物成功构建了 2,5 -双取代的呋喃类化合物 177
(Scheme 29). Tsuji 小组开发的方法实现了相同底物在不 同催化剂作用下生成不同结构骨架的两种产物，是值得 借鉴的反应条件控制的多样性合成策略范例.

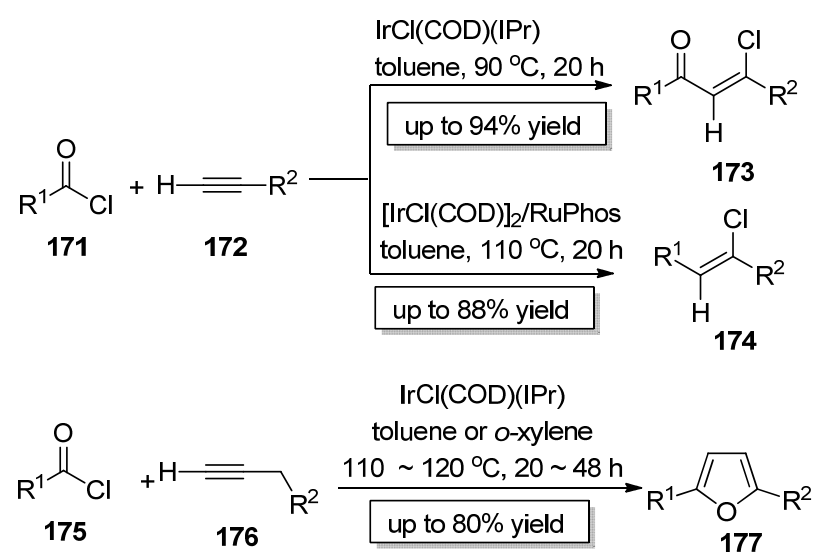

图式 29 铱催化 $\mathrm{C}\left(\mathrm{sp}^{2}\right)-\mathrm{Cl}$ 键对炔键的分子间加成 Scheme 29 Ir-catalyzed intermolecular addition of $\mathrm{C}\left(\mathrm{sp}^{2}\right)-\mathrm{Cl}$ bond to alkynes

2015 年, Lautens 课题组 ${ }^{[65]}$ 报道了钯催化芳卤类化 合物 178 中的 $\mathrm{C}\left(\mathrm{sp}^{2}\right)-\mathrm{X}(\mathrm{X}=\mathrm{Cl}, \mathrm{Br}, \mathrm{I})$ 键对非末端炔键 的分子内加成(Scheme 30). 当反应温度为 $50{ }^{\circ} \mathrm{C}$ 时, 反 应主要选择性得到顺式加成的五元环产物 cis-179 (Scheme 30), 有趣的是, 当反应温度升高至 $100{ }^{\circ} \mathrm{C}$ 时,
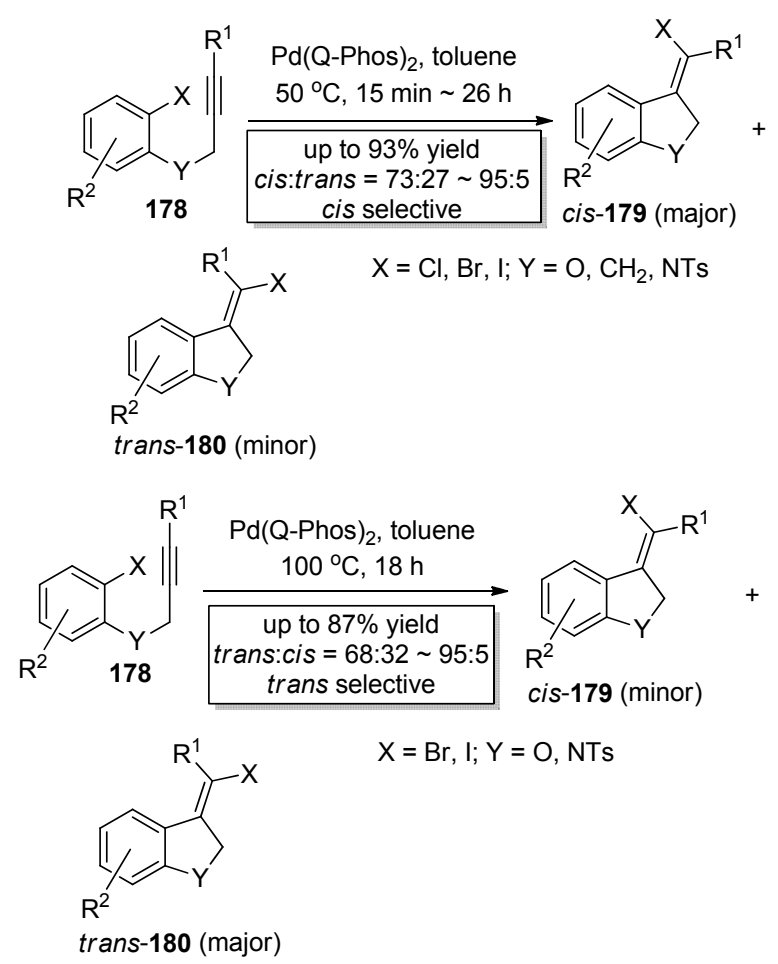

图式 30 钯催化 $\mathrm{C}\left(\mathrm{sp}^{2}\right)-\mathrm{X}(\mathrm{X}=\mathrm{Cl}, \mathrm{Br}, \mathrm{I})$ 键对㶧键的分子内加 成

Scheme 30 Pd-catalyzed intramolecular addition of $\mathrm{C}\left(\mathrm{sp}^{2}\right)-\mathrm{X}$ $(\mathrm{X}=\mathrm{Cl}, \mathrm{Br}$, I) bond to alkynes 
由于顺式加成产物向反式加成产物发生异构, 反应主要 选择性得到反式加成的五元环产物 trans-180 (Scheme 30), 如此, 通过控制反应温度即可选择性得到两个立 体异构体. 此反应的反应历程涉及钯催化剂对 $\mathrm{C}-\mathrm{X}$ 键 的氧化加成、 $\mathrm{C}-\mathrm{Pd}$ 键对炔键的分子内加成和钯催化剂 的还原消除三步, 然而钯催化剂对 $\mathrm{C}-\mathrm{X}$ 键的氧化加成 一般是受加热促进而且是不可逆的, 也就是说要实现钯 催化剂从 $\mathrm{ArPd}^{\mathrm{II} X}$ 复合物的还原消除是非常具有挑战性 的 ${ }^{[66]}$. Lautens 等正是在这种挑战下, 利用大位阻的催化 剂和大位阻的底物实现了钯催化剂从 $\mathrm{ArPd}^{\mathrm{II}} \mathrm{X}$ 复合物的 还原消除, 从而实现芳卤类化合物中的 $\mathrm{C}-\mathrm{X}$ 键对炔键 的分子内加成，合成了交叉偶联反应常用的烯基卤类合 成砌块.

\subsection{3 $\mathrm{C}\left(\mathrm{sp}^{3}\right)-\mathrm{X}(\mathrm{X}=\mathrm{Cl}, \mathrm{Br}, \mathrm{I})$ 键对炔键的加成}

2009 年, Liu 课题组 ${ }^{[67]}$ 报道了苄卤类化合物 181 中 的 $\mathrm{C}\left(\mathrm{sp}^{3}\right)-\mathrm{X}(\mathrm{X}=\mathrm{Cl}, \mathrm{Br})$ 键对炔 182 的分子间加成 (Scheme 31), 该反应以价廉易得的 $\mathrm{FeCl}_{3} \cdot 6 \mathrm{H}_{2} \mathrm{O}$ 为催化 剂, 在二氯甲烷中于 $50{ }^{\circ} \mathrm{C}$ 反应 $12 \mathrm{~h}$ 即可以较高产率主 要获得反式加成产物 183 , 该反应系首次实现铁催化 $\mathrm{C}\left(\mathrm{sp}^{3}\right)-\mathrm{X}(\mathrm{X}=\mathrm{Cl}, \mathrm{Br})$ 键对炔键的分子间加成. 随后, $\mathrm{Hu}$ 小组 ${ }^{[68]}$ 于 2015 年报道了 $\mathrm{Cu}(\mathrm{OTf})_{2}$ 催化的 $\mathrm{C}-\mathrm{I}$ 键对 炔键的分子间加成(Scheme 31), 羰基 $\alpha$ 位溴代的含有一
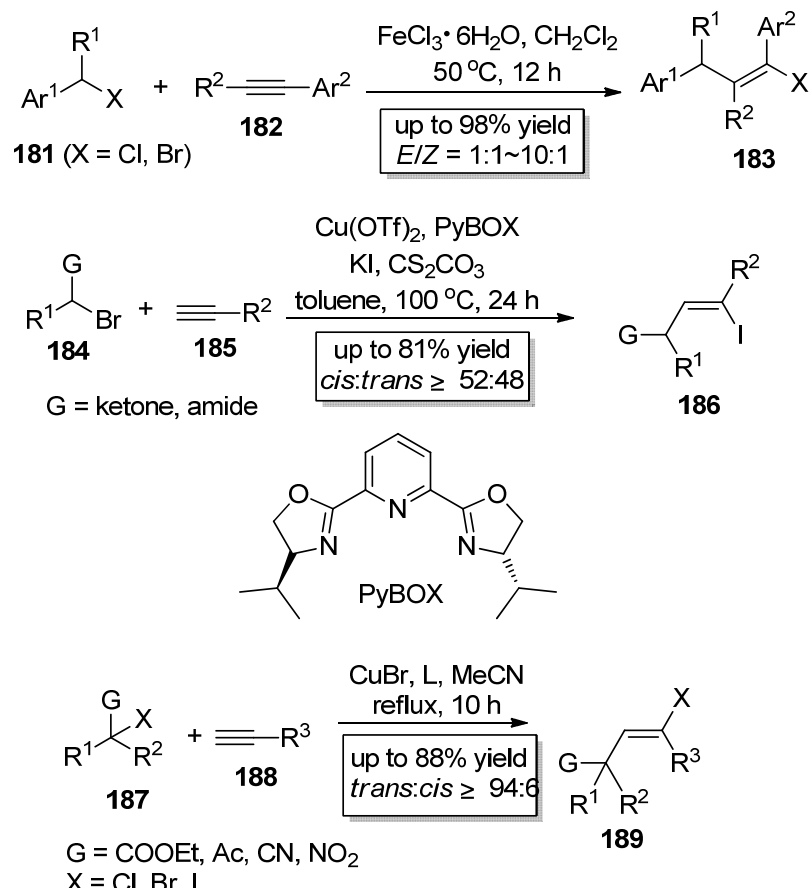<smiles>[CH]CN(C)CCN(C)CCN(C)C</smiles>

图式 31 铁或铜催化 $\mathrm{C}\left(\mathrm{sp}^{3}\right)-\mathrm{X}(\mathrm{X}=\mathrm{Cl}, \mathrm{Br}, \mathrm{I})$ 键对炔键的分子 间加成

Scheme $31 \mathrm{Fe}$ or $\mathrm{Cu}$-catalyzed intermolecular addition of $\mathrm{C}\left(\mathrm{sp}^{3}\right)-\mathrm{X}(\mathrm{X}=\mathrm{Cl}, \mathrm{Br}, \mathrm{I})$ bond to alkynes
个叔碳中心的酰胺或酮类底物 184 先与 $\mathrm{KI}$ 发生卤素置 换反应生成羰基 $\alpha$ 位碘代的中间体，该中间体结构中的 $\mathrm{C}$ - I 键进一步在 $\mathrm{Cu}(\mathrm{OTf})_{2}$ 催化下与端炔 185 发生加成 反应. 该反应区域选择性高，碘原子只加成到非末端炔 碳上，但该反应立体化学选择性整体上欠佳. $\mathrm{Hu}$ 小组开 发的方法为合成 $\beta, \gamma$-不饱和酮和酰胺这两类化合物提供 了便捷的路径，他们还将开发的方法用于组蛋白去乙酰 化酶抑制剂 $( \pm)$-trichostatin A 的合成中. 继 $\mathrm{Hu}$ 小组的工 作之后, Zhu 课题组 ${ }^{[69]}$ 紧接着报道了 $\mathrm{CuBr}$ 催化的含有一 个季碳中心的底物 187 中的 $\mathrm{C}\left(\mathrm{sp}^{3}\right)-\mathrm{X}(\mathrm{X}=\mathrm{Cl}, \mathrm{Br})$ 键对 端炔 188 的分子间加成(Scheme 31), 值得注意的是, 他 们在底物中引入了 $1 \sim 2$ 个强吸电子基团用于活化 $\mathrm{C}\left(\mathrm{sp}^{3}\right)-\mathrm{X}$ 键. 该反应的区域选择性极好，甾原子只加 成到非末端炔碳上; 该反应的立体化学选择性非常好, 而且与 $\mathrm{Hu}$ 小组所报道方法的立体化学选择性非相反, 几乎只得到反式加成产物 189 (trans : cis $\geqslant 94: 6$ ).

2011 年, $\mathrm{Zhu}$ 课题组 ${ }^{[70]}$ 以 $\mathrm{Pd}(\mathrm{OAc})_{2}$ 为催化剂实现了 烯丙基卤 190 中的 $\mathrm{C}\left(\mathrm{sp}^{3}\right)-\mathrm{X}(\mathrm{X}=\mathrm{Cl}, \mathrm{Br})$ 键对炔基卤 191 的分子间加成(Scheme 32), 该反应不但操作简单, 且底物适用范围广、产率高, 而且区域选择性和立体化 学选择性极好, 几乎只以顺式加成的形式得到 $E$ 式产物 192. 同年他们又报道了 $\mathrm{PdCl}_{2}$ 催化的烯丙基氯 193 中的
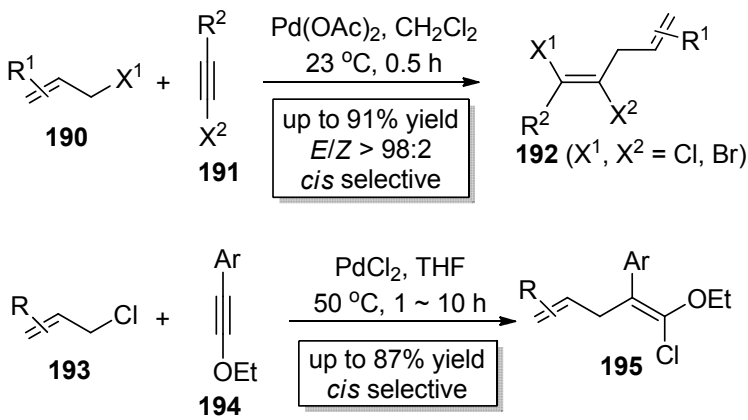

$\mathrm{Cu}(\mathrm{OTf})_{2}, \mathrm{KF}$

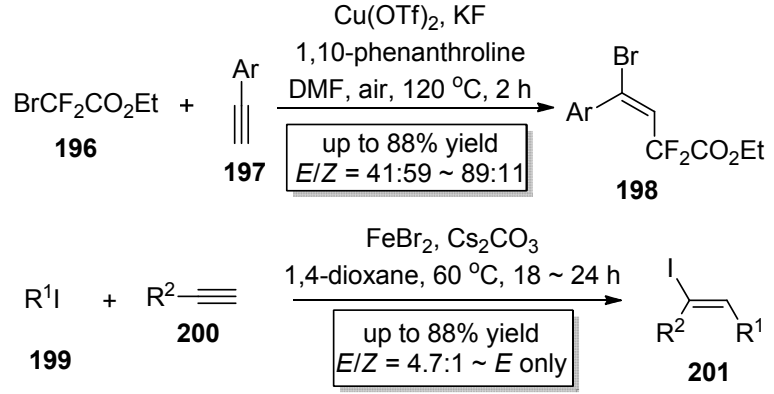

$\mathrm{R}^{1} \mathrm{I}=\mathrm{CF}_{3} \mathrm{I}, \mathrm{C}_{n} \mathrm{~F}_{2 n+1} \mathrm{I}, \mathrm{ICF}_{2} \mathrm{CO}_{2} \mathrm{Et}$

图式 32 钯、铜、铁催化 $\mathrm{C}\left(\mathrm{sp}^{3}\right)-\mathrm{X}(\mathrm{X}=\mathrm{Cl}, \mathrm{Br}, \mathrm{I})$ 键对炔键的 分子间加成

Scheme $32 \mathrm{Pd}, \mathrm{Cu}, \mathrm{Fe}$-catalyzed intermolecular addition of $\mathrm{C}\left(\mathrm{sp}^{3}\right)-\mathrm{X}(\mathrm{X}=\mathrm{Cl}, \mathrm{Br}, \mathrm{I})$ bond to alkynes 
$\mathrm{C}\left(\mathrm{sp}^{3}\right)-\mathrm{Cl}$ 键对炔基乙基醚 194 的分子间加成(Scheme $32)^{[71]}$, 以较高的收率主要得到了顺式加成产物 195. 2014 年, Poisson 小组 ${ }^{[72]}$ 报道了 $\mathrm{Cu}(\mathrm{OTf})_{2}$ 催化的多氟代 底物二氟溴乙酸乙酯 196 中的 $\mathrm{C}\left(\mathrm{sp}^{3}\right)-\mathrm{Br}$ 键对炔 197 的 分子间加成(Scheme 32), 尽管该反应立体化学选择性 欠佳, 但是成功地将二氟亚甲基引入到了炔基碳上. 值 得一提的是, $\mathrm{Hu}$ 小组同时独立地报道了 $\mathrm{FeBr}_{2}$ 催化的多 氟取代的碘代烷烃 199 中的 $\mathrm{C}-\mathrm{I}$ 键对炔键的分子间加 成(Scheme 32) ${ }^{[73]}$, 与 Poisson 小组报道的方法相比, 该 方法立体化学选择性高, 主要得到多氟代的反式加成产 物 201. 以上方法都可以快速构建可用于交叉偶联反应 的烯基卤这一重要的合成砌块, 尤其是 $\mathrm{Hu}$ 小组发展的 方法为合成多氟代的烯基碘提供了实用而高效的方 法 $^{[74]}$.

\section{$1.8 \mathrm{C}$ - Se 键对炔键的加成}

2005 年, Kambe 课题组 ${ }^{[54]}$ 报道了 $\mathrm{Pd}\left(\mathrm{PPh}_{3}\right)_{4}$ 催化的 硒代酯 202 中 $\mathrm{C}-\mathrm{Se}$ 键对 1-辛炔的分子间加成, 此反应 具有区域选择性和立体选择性高(顺式加成)的特点, 几 乎只获得单一构型的目标产物 204, 该反应可以实现对 炔碳的酰胺化从而构建 $\alpha, \beta$-不饱和酰胺类化合物 (Scheme 33). 他们进一步设计了底物 205 来考察 $\mathrm{C}-\mathrm{Se}$ 键对炔键的分子内加成的可能性, 实验证明 $\mathrm{C}-\mathrm{Se}$ 键对 炔键的分子内加成同样可行, 该反应不但区域选择性 高, 而且立体选择性好 $(E: Z=11: 89 \sim 0: 100)$, 主要 生成 $Z$ 式构型四元内酰胺产物 206 (Scheme 33). 当增加 炔基和氮原子之间的碳原子个数至 3 或 4 时, 反应仍然 可以顺利进行, 只生成 $Z$ 式构型的六元或七元内酰胺产 物(Scheme 33): 有趣的是, 当使用氮原子上连接两个不 同碳链长度的炔基取代基的化合物 209 为底物时, 反应 优先生成四元内酰胺产物 210 而非六元内酰胺产物 211 (Scheme 33). Kambe 课题组还推测了此反应可能的反应 机理(Scheme 34), 与一价、二价、四价金属催化的类似 反应不同, 此类反应可能涉及 $\mathrm{Pd}$ 对 $\mathrm{C}-\mathrm{Se}$ 键的氧化加 成以及 $\mathrm{Pd}$ 与炔基 $\pi$ 电子的配位, $\mathrm{Pd}$ 或先与 $\mathrm{C}-\mathrm{Se}$ 键进 行氧化加成生成中间体 $\mathbf{A 5}$ 再与炔基 $\pi$ 电子配位生成中 间体 B5, 或 Pd 先与炔基 $\pi$ 电子配位生成中间体 $\mathbf{A 5}$ '再 与 $\mathrm{C}$ - $\mathrm{Se}$ 键进行氧化加成生成中间体 $\mathbf{B 5}$, 然后 Pd-Se 键再对炔键进行加成生成中间体 C5, 最后经过还原消 除得到产物 206 并释放出催化剂.

\section{2 碳一杂键对炔键的加成反应在合成天然产物 中的应用}

Vibsanol (213) 是从植物Viburnum awabuki 中分离得 到的具有脂质过氧化作用抑制活性的天然产物 ${ }^{[75 ~ 77]}$, 其母核结构为 2,3,5,7 位四取代的苯并呋喃, 而且其结构
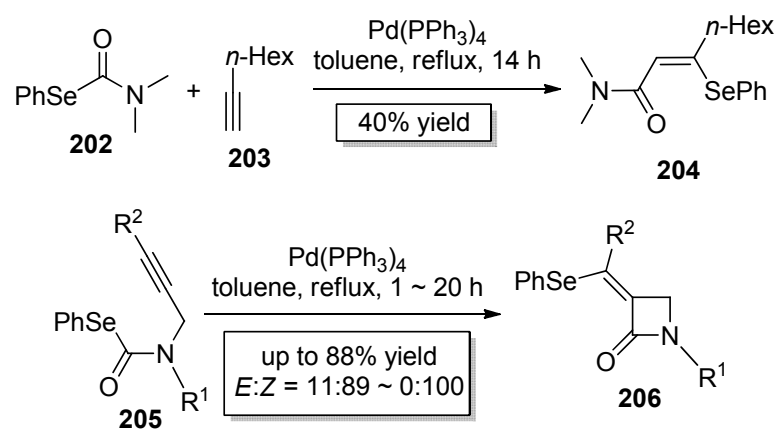

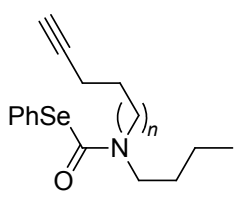

207
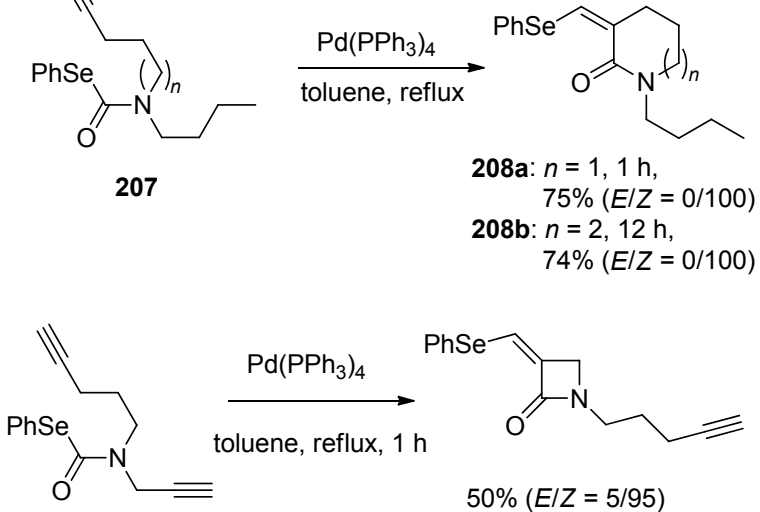

209<smiles>C#CCN1CCC/C(=C/[SeH2]c2ccccc2)C1=O</smiles>

$10 \%(E / Z=11 / 89)$

211

图式 33 钯催化 C-Se 键对炔键的加成

Scheme 33 Pd-catalyzed addition of $\mathrm{C}-$ Se bond to alkynes

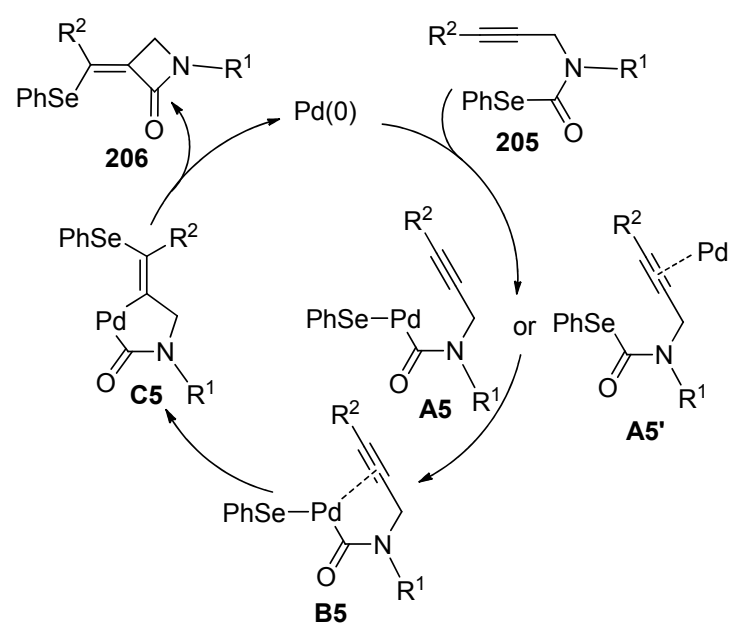

图式 34 钯催化 $\mathrm{C}$ - $\mathrm{Se}$ 键对炔键的加成反应机理 Scheme 34 Proposed reaction mechanism of Pd-catalyzed addition of $\mathrm{C}-\mathrm{Se}$ bond to alkynes

中存在 4 个裸露的羟基，羟基被保护基团保护的化合物 
212 是合成 Vibsanol 的关键前体(Eq. 3). 2005 年, Yamamoto 小组 ${ }^{[30]}$ 构建了底物 216 并采用铂催化的 C$\mathrm{O}$ 键对炔键的分子内加成反应一步高效地构建了合成 Vibsanol 所必需的关键前体 217. 与之前文献报道的合 成 Vibsanol 的关键前体的方法相比，该方法避免了羟基 的反复保护与脱保护, 缩短了反应步骤, 提高了总收率 (Scheme 35).
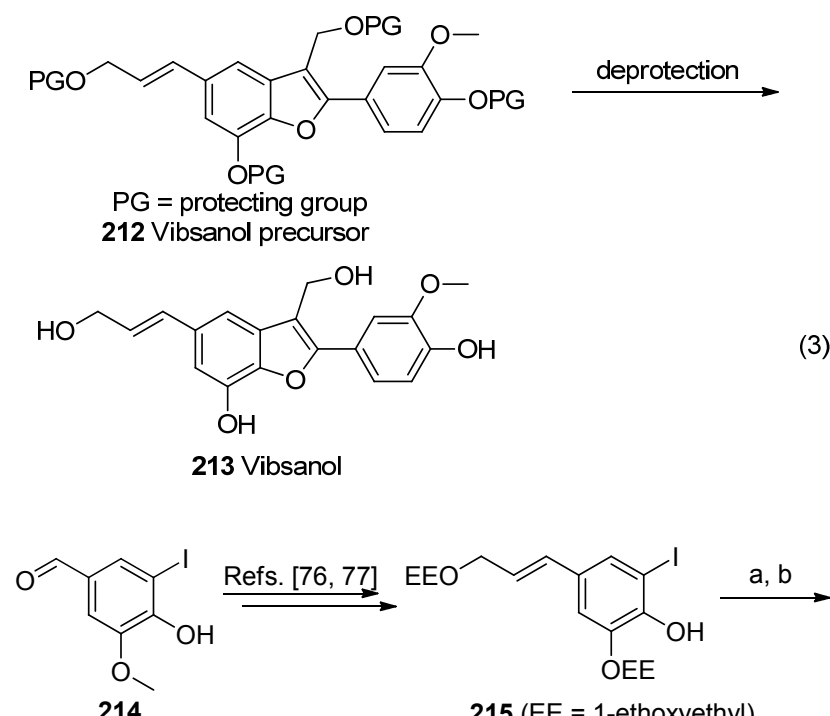<smiles>CCOCC=Cc1cc(C#Cc2ccc(OCC)c(OC)c2)c(OCc2ccccc2)c(OCC)c1</smiles>

216<smiles>CCCOc1cc(/C=C/COC)cc2c(COCC)c(-c3ccc(OCC)c(OC)c3)oc12</smiles>

Reagent and conditions: (a) $\mathrm{BOMCl}, \mathrm{NaH}, \mathrm{THF}, 0{ }^{\circ} \mathrm{C}$, quantitative yield; (b) [4-(1-ethoxyethyl)-3-methoxyphenyl]acetylene, $\mathrm{Pd}\left(\mathrm{PPh}_{3}\right)_{4}$, Cul, $\mathrm{Et}_{3} \mathrm{~N}$, THF, r.t., $64 \%$; (c) $20 \mathrm{~mol}^{2} \mathrm{PtCl}_{2}, 80 \mathrm{~mol} \% \mathrm{COD}$, toluene, $30{ }^{\circ} \mathrm{C}, 76 \%$.

图式 $35 \mathrm{Vibsanol}$ 关键前体的合成

Scheme 35 Synthesis of the key precursor of Vibsanol

\section{3 结论与展望}

随着合成方法学的不断发展，有机化学家们发展了 多种金属, 如 $\mathrm{Al}, \mathrm{Fe}, \mathrm{Ni}, \mathrm{Cu}, \mathrm{Ga}, \mathrm{Ru}, \mathrm{Rh}, \mathrm{Pd}, \mathrm{Hf}, \mathrm{Ir}, \mathrm{Pt}$, $\mathrm{Au}, \mathrm{Bi}$ 等催化的诸多类型的碳一杂键对炔键的加成反应, 这些加成反应已经超出了传统的简单小分子对炔键的 分子间加成反应的范畴, 极大地丰富了加成反应的内涵 并拓展了加成反应的应用范围. 根据对炔键进行加成的
碳一杂键的类型分为 $\mathrm{C}-\mathrm{H}, \mathrm{C}-\mathrm{B}, \mathrm{C}-\mathrm{N}, \mathrm{C}-\mathrm{O}, \mathrm{C}-\mathrm{Si}$, $\mathrm{C}-\mathrm{S}, \mathrm{C}-\mathrm{X}(\mathrm{X}=\mathrm{Cl}, \mathrm{Br}, \mathrm{I}), \mathrm{C}-\mathrm{Se}$ 键这 8 类并对各类加 成反应的反应条件、反应选择性(区域选择性和立体化 学选择性)和反应机理进行了讨论和总结, 阐述了该类 合成方法在天然产物合成中的应用。

尽管金属催化的碳一杂键对炔键的加成反应在近年 来取得了重要进展, 然而在此研究领域仍然存在许多挑 战. 如目前使用的大部分金属催化剂仍是价格较昂贵的 $\mathrm{Ru}, \mathrm{Rh}, \mathrm{Pd}, \mathrm{Ni}, \mathrm{Ir}, \mathrm{Pt}, \mathrm{Au}$ 等催化剂，而且目前报道的许 多类型的碳一杂键对炔键的加成反应仅局限于分子内而 不能适用于分子间，此外还有许多类型的碳-杂键对炔 键的加成反应尚未实现. 我们相信在不久的将来在此领 域会有更多突破性的进展，使得金属催化的碳一杂键对 炔键的加成反应成为对炔键进行官能团化的一种重要 策略，并在有机合成中发挥更加重要的作用.

\section{References}

[1] (a) Chinchilla, R.; Nájera, C. Chem. Rev. 2014, 114, 1783.

(b) Huang, L.; Arndt, M.; Gooßen, K.; Heydt, H.; Gooßen, L. J. Chem. Rev. 2015, 115, 2596.

(c) Cacchi, S.; Fabrizi, G. Chem. Rev. 2005, 105, 2873.

(d) Boyarskiy, V. P.; Ryabukhin, D. S.; Bokach, N. A.; Vasilyev, A. V. Chem. Rev. 2016, 116, 5894

(e) Thirumurugan, P.; Matosiuk, D.; Jozwiak, K. Chem. Rev. 2013, 113, 4905.

(f) Tiwari, V. K.; Mishra, B. B.; Mishra, K. B.; Mishra, N.; Singh, A. S.; Chen, X. Chem. Rev. 2016, 116, 3086.

(g) Daniel, F.; Harvey, D. M. S. Chem. Rev. 1996, 96, 271.

(h) Krause, N.; Winter, C. Chem. Soc. Rev. 2011, 40, 1994.

(i) Hirner, J. J.; Shi, Y.; Blum, S. A. Acc. Chem. Res. 2011, 44, 603.

(j) Pina, C. D.; Falletta, E.; Rossi, M. Chem. Soc. Rev. 2012, 41 350 .

(k) Stratakis, M.; Garcia, H. Chem. Rev. 2012, 112, 4469.

(1) Rudolph, M.; Hashmi, A. S. K. Chem. Soc. Rev. 2012, 41, 2448.

(m) Liu, L.-P.; Hammond, G. B. Chem. Soc. Rev. 2012, 41, 3129.

(n) Platon, M.; Amardeil, R.; Djakovitch, L.; Hierso, J. C. Chem. Soc. Rev. 2012, 41, 3929.

(o) Shiri, M. Chem. Rev. 2012, 112, 3508

(p) Abbiati, G.; Marinelli, F.; Rossi, E.; Arcadi, A. Isr. J. Chem. 2013, 53, 856 .

(q) Cariou, K.; Ronan, B.; Mignani, S.; Fensterbank, L.; Malacria, M. Angew. Chem., Int. Ed. 2007, 46, 1881.

(r) Hashmi, A. S. K.; Graf, K.; Ackermann, M.; Rominger, F. ChemCatChem 2013, 5, 1200.

(s) Kolundžić, F.; Murali, A.; Pérez-Galán, P.; Bauer, J. O.; Strohmann, C.; Kumar, K.; Waldmann, H. Angew. Chem., Int. Ed. 2014, 53, 8122.

(t) Tokimizu, Y.; Oishi, S.; Fujii, N.; Ohno, H. Angew. Chem., Int. Ed. 2015, 54, 7862.

(u) Zhu, H.; Yan, B.-Y.; Cao, Y.; Chen, Z.-Y. Chin. J. Org. Chem. 2015, 35, 509 (in Chinese).

(朱辉, 严冰玉, 曹杨, 陈知远，有机化学, 2015, 35, 509.)

(v) Wang, M.-M.; Wang, Z.-X.; Shang, M.; Dai, H.-X. Chin. J. Org. Chem. 2015, 35, 570 (in Chinese).

(王明明，王子萧，商明，戴辉雄，有机化学, 2015, 35, 570.)

(w) Wu, C.-R.; Yang, Y.-P.; Shi, F. Chin. J. Org. Chem. 2015, 35, 
770 (in Chinese).

(吴春荵，杨玉坡，史峰，有机化学，2015, 35, 770.)

(x) Zhou, P.; Qiu, H.-H.; Shi, J.-C. Chin. J. Org. Chem. 2016, 36, 425 (in Chinese).

(周鹏，邱会华，施继成，有机化学，2016, 36, 425.)

(y) Wen, Z.-G.; Tian, C.; Borzov, M. V.; Nie, W.-L Acta Chim. Sinica 2016, 74, 498 (in Chinese).

(温志国, 田冲, Borzov, M. V., 聂万丽, 化学学报, 2016, 74, 498.) (z) Wang, J.; Cui, D.-M. Chin. J. Org. Chem. 2016, 36, 1163 (in Chinese).

(王剑, 崔冬梅, 有机化学, 2016, 36, 1163.)

[2] Kobayashi, Y.; Kamisaki, H.; Yanada, K.; Yanada, R.; Takemoto, Y. Tetrahedron Lett. 2005, 46, 7549.

[3] Nakao, Y.; Idei, H.; Kanyiva, K. S.; Hiyama, T. J. Am. Chem. Soc. 2009, 131, 5070.

[4] Fujihara, T.; Katafuchi, Y.; Iwai, T.; Terao, J.; Tsuji, Y. J. Am. Chem. Soc. 2010, 132, 2094.

[5] (a) Lindhardt, A. T.; Mantel, M. L. H.; Skrydstrup, T. Angew. Chem., Int. Ed. 2008, 47, 2668.

(b) Hills, I. D.; Fu, G. C. J. Am. Chem. Soc. 2004, 126, 13178.

(c) Grushin, V. V. Chem. Rev. 1996, 96, 2011.

[6] Trost, B. M.; Lumb, J. P.; Azzarelli, J. M. J. Am. Chem. Soc. 2011, 133,740

[7] Trost, B. M.; Taft, B. R.; Masters, J. T.; Lumb, J. P. J. Am. Chem. Soc. 2011, 133, 8502 .

[8] Xu, H.-D.; Zhang, R.-W.; Li, X.; Huang, S.; Tang, W.; Hu, W.-H. Org. Lett. 2013, 15, 840.

[9] Liu, G.; Kong, W.; Che, J.-W.; Zhu, G.-G. Adv. Synth. Catal. 2014, $356,3314$.

[10] Babu, M. H.; Dwivedi, V.; Kant, R.; Reddy, M. S. Angew. Chem., Int. Ed. 2015, 54, 3783.

[11] For more examples of hydroalkynylation of alkynes, see: (a) Katayama, H.; Yari, H.; Tanaka, M.; Ozawa, F. Chem. Commun. 2005, 4336.

(b) Bassetti, M.; Pasquini, C.; Raneri, A.; Rosato, D. J. Org. Chem. 2007, 72, 4558 .

(c) Jahier, C.; Zatolochnaya, O. V.; N. Zvyagintsev, V. V.; Ananikov, P.; Gevorgyan, V. Org. Lett. 2012, 14, 2846.

(d) Chen, T.; Guo, C.; Goto, M.; Han, L.-B. Chem. Commun. 2013, 49, 7498 .

(e) Xu, C.; Du, W.; Zeng, Y.; Dai, B.; Guo, H. Org. Lett. 2014, 16, 948.

(f) Platel, R. H.; Schafer, L. L. Chem. Commun. 2012, 48, 10609.

(g) Midya, G. C.; Parasar, B.; Dhara, K.; Dash, J. Org. Biomol. Chem. 2014, 12, 1812.

(h) Ventre, S.; Derat, E.; Amatore, M.; Aubert, C.; Petit, M. $A d v$. Synth. Catal. 2013, 355, 2584.

(i) Shen, R.-W.; Chen, K.; Deng, Q.-L.; Yang, J.-J.; Zhang, L.-X. Org. Lett. 2014, 16, 1208.

[12] Suginome, M.; Yamamoto, A.; Murakami, M. J. Am. Chem. Soc. 2003, 125, 6358 .

[13] Suginome, M.; Yamamoto, A.; Murakami, M. Angew. Chem., Int. Ed. 2005, 44, 2380.

[14] (a) Harwood, H. J. Jr.; Barbacci-Tobin, E. G.; Petras, S. F.; Lindsey, S.; Pellarin, L. D. Biochem. Pharmacol. 1997, 53, 839.

(b) Morand, P.; Bagli, J. F.; Kraml, M.; Dubuc, J. J. Med. Chem. 1964, 7, 504.

[15] Suginome, M.; Shirakura, M.; Yamamoto, A. J. Am. Chem. Soc. 2006, $128,14438$.

[16] Shimada, T.; Nakamura, I.; Yamamoto, Y. J. Am. Chem. Soc. 2004, 126,10546

[17] Nakamura, I.; Sato, Y.; Konta, S.; Terada, M. Tetrahedron Lett.
2009, 50, 2075.

[18] Wu, C.-Y.; Hu, M.; Liu, Y.; Song, R.-J.; Lei, Y.; Tang, B.-X.; Li, R.-J.; Li, J.-H. Chem. Commun. 2012, 48, 3197.

[19] Zhao, F.; Zhang, D.-Y.; Nian, Y.; Zhang, L.; Yang, W.; Liu, H. Org. Lett. 2014, 16, 5124.

[20] Wu, C.-L.; Zhao, F.; Shu, S.-J.; Wang, J.; Liu, H. RSC Adv. 2015, 5, 90396.

[21] Wu, C.-L.; Zhao, F.; Du, Y.-L.; Zhao, L.; Chen, L.; Wang, J.; Liu, H. $R S C A d v$. 2016, 6, 70682.

[22] Kamijo, S.; Yamamoto, Y. J. Am. Chem. Soc. 2002, 124, 1940.

[23] Majumdar, K. C.; Hazra, S.; Roy, B. Tetrahedron Lett. 2011, 52, 6697.

[24] Heugebaert, T. S.; Stevens, C. V. Org. Lett. 2009, 11, 5018.

[25] Nakamura, I.; Mizushima, Y.; Yamagishi, U.; Yamamoto, Y. Tetrahedron 2007, 63, 8670.

[26] Zeng, X.-M.; Kinjo, R.; Donnadieu, B.; Bertrand, G. Angew. Chem., Int. Ed. 2010, 49, 942.

[27] Filatova, E. A.; Pozharskii, A. F.; Gulevskaya, A. V.; Ozeryanskii, V. A. J. Org. Chem. 2015, 80, 872.

[28] For more examples of addition of $\mathrm{C}-\mathrm{N}$ bond to alkynes, see: (a) Nakamura, I.; Yamagishi, U.; Song, D.; Konta, S.; Yamamoto, Y. Chem. Asian J. 2008, 3, 285.

(b) Tobisu, M.; Ano, Y.; Chatani, N. Org. Lett. 2009, 11, 3250.

(c) Cacchi, S.; Fabrizi, G.; Pace, Paola. J. Org. Chem. 1998, 63, 1001.

(d) Li, G.-T.; Huang, X.-G.; Zhang, L.-M. Angew. Chem., Int. Ed. 2008, 47, 346.

[29] Cacchi, S.; Fabrizi, G.; Moro, L. Tetrahedron Lett. 1998, 39, 5101.

[30] Nakamura, I.; Mizushima, Y.; Yamamoto, Y. J. Am. Chem. Soc. $\mathbf{2 0 0 5}, 127,15022$.

[31] Fürstner, A.; Davies, P. W. J. Am. Chem. Soc. 2005, 127, 15024.

[32] Liang, Z.-Q.; Ma, S.-M.; Yu, J.-H.; Xu, R.-R. J. Org. Chem. 2007, $72,9219$.

[33] Dubé, P.; Toste, F. D. J. Am. Chem. Soc. 2006, 128, 12062.

[34] Nakamura, I.; Chan, C. S.; Araki, T.; Terada, M.; Yamamoto, Y. Org. Lett. 2008, 10, 309.

[35] (a) Miki, K.; Nishino, F.; Ohe, K.; Uemura, S. J. Am. Chem. Soc. 2002, 124, 5260 .

(b) Nevado, C.; Cárdenas, D. J.; Echavarren, A. M. Chem. Eur. J. 2003, 9, 2627.

(c) Harrak, Y.; Blaszykowski, C.; Bernard, M.; Cariou, K.; Mainetti, E.; Mourie`s, V.; Dhimane, A.-L.; Fensterbank, L.; Malacria, M. J. Am. Chem. Soc. 2004, 126, 8656.

(d) Kusama, H.; Miyashita, Y.; Takaya, J.; Iwasawa, N. Org. Lett. 2006, 8,289

[36] Nakamura, I.; Chan, C. S.; Araki, T.; Terada, M. Yamamoto, Y. $A d v$. Synth. Catal. 2009, 351, 1089.

[37] Komeyama, K.; Takahashi, K.; Takaki, K. Org. Lett. 2008, 10, 5119.

[38] Shi, Y.; Roth, K. E.; Ramgren, S. D.; Blum, S. A. J. Am. Chem. Soc. 2009, 131, 18022.

[39] Ueda, M.; Sato, A.; Ikeda, Y.; Miyoshi, T.; Naito, T.; Miyata, O. Org. Lett. 2010, 12, 2594.

[40] Watanabe, K.; Mino, T.; Ikematsu, T.; Hatta, C.; Yoshida, Y.; Sakamoto, M. Org. Chem. Front. 2016, 3, 979.

[41] For more examples of addition of $\mathrm{C}-\mathrm{O}$ bond to alkynes, see: (a) Ackermann, M.; Bucher, J.; Rappold, M.; Graf, K.; Rominger, F.; Hashmi, A. S. Chem. Asian J. 2013, 8, 1786.

(b) Hashmi, A. S. K.; Lothschütz, C.; Döpp, R.; Ackermann, M.; Becker, J. D. B.; Rudolph, M.; Scholz, C.; Rominger, F. Adv. Synth. Catal. 2012, 354, 133.

(c) Monteiro, N.; Balme, G. Synlett 1998, 746. 
(d) Fürstner, A.; Heilmann, E. K.; Davies, P. W. Angew. Chem., Int. Ed. 2007, 46, 4760

(e) Tsuda, T.; Ohashi, Y.; Nagahama, N.; Sumiya, R.; Saegusa, T. J. Org. Chem. 1988, 53, 2650.

(f) Obata, T.; Suzuki, S.; Nakagawa, A.; Kajihara, R.; Noguchi, K.; Saito, A. Org. Lett. 2016, 18, 4136.

[42] Yeon, S. Ho.; Han, J. S.; Hong, E.; Do, Y.; Jung, I. N. J. Organomet. Chem. 1995, 499, 159.

[43] Asao, N.; Yoshikawa, E.; Yamamoto, Y. J. Org. Chem. 1996, 61, 4874.

[44] Yoshikawa, E.; Gevorgyan, V.; Asao, N.; Yamamoto, Y. J. Am. Chem. Soc. 1997, 119, 6781 .

[45] Asao, N.; Tomeba, H.; Yamamoto, Y. Tetrahedron Lett. 2005, 46, 27.

[46] Asao, N.; Shimada, T.; Yamamoto, Y. J. Am. Chem. Soc. 1999, 121, 3797.

[47] Asao, N.; Shimada, T.; Shimada, T.; Yamamoto, Y. J. Am. Chem. Soc. 2001, 123, 10899.

[48] Matsuda, T.; Kadowaki, S.; Yamaguchi, Y.; Murakami, M. Chem. Commun. 2008, 2744

[49] Matsuda, T.; Yamaguchi, Y.; Shigeno, M.; Sato, S.; Murakami, M. Chem. Commun. 2011, 47, 8697.

[50] Zhou, T.; Xia, Y.-Z. Organometallics 2014, 33, 4230.

[51] Imamura, K.; Yoshikawa, E.; Gevorgyan, V.; Yamamoto, Y. J. Am. Chem. Soc. 1998, 120, 5339.

[52] Nakamura, I.; Bajracharya, G. B.; Wu, H.; Oishi, K.; Mizushima, Y.; Gridnev, I. D.; Yamamoto, Y. J. Am. Chem. Soc. 2004, 126, 15423.

[53] Nakamura, I.; Sato, T.; Terada, M.; Yamamoto, Y. Org. Lett. 2008, $10,2649$.

[54] Toyofuku, M.; Fujiwara, S.; Shinike, T.; Kuniyasu, H.; Kambe, N. J. Am. Chem. Soc. 2005, 127, 9706.

[55] Kamiya, I.; Kawakami, J.; Yano, S.; Nomoto, A.; Ogawa, A. Organometallics. 2006, 25, 3562.

[56] Nakamura, I.; Sato, T.; Yamamoto, Y. Angew. Chem., Int. Ed. 2006, $45,4473$.

[57] Hooper, J. F.; Chaplin, A. B.; González-Rodríguez, C.; Thompson, A. L.; Weller, A. S.; Willis, M. C. J. Am. Chem. Soc. 2012, 134, 2906.

[58] For more examples of addition of $\mathrm{C}-\mathrm{S}$ bond to alkynes, see: (a) Lee, Y. T.; Choi, S. Y.; Chung, Y. K. Tetrahedron Lett. 2007, 48, 5673 .

(b) Davies, P. W.; Albrecht, S. J. C. Chem. Commun. 2008, 238.

[59] Li, Y.-B.; Liu, X.-H.; Jiang, H.-F.; Feng, Z.-N. Angew. Chem., Int. Ed. 2010, 49, 3338.

[60] Murai, M.; Hatano, Ryo.; Kitabata, S.; Ohe, K. Chem. Commun. 2011, 47, 2375.

[61] Hua, R.; Shimada, S.; Tanaka, M. J. Am. Chem. Soc. 1998, 120,
12365

[62] Kashiwabara, T.; Fuse, K.; Hua, R.; Tanaka, M. Org. Lett. 2008, 10, 5469.

[63] Fielding, M. R.; Grigg, R.; Urchb, C. J. Chem. Commun. 2000, 2239.

[64] Iwai, T.; Fujihara, T.; Terao, J.; Tsuji, Y. J. Am. Chem. Soc. 2009, 131, 6668.

[65] Le, C. M.; Menzies, P. J. C.; Petrone, D. A.; Lautens, M. Angew. Chem., Int. Ed. 2015, 54, 254.

[66] (a) Legault, C. Y.; Garcia, Y.; Merlic, C. A.; Houk, K. N. J. Am. Chem. Soc. 2007, 129, 12664.

(b) Xue, L.; Lin, Z. Chem. Soc. Rev. 2010, 39, 1692.

(c) García-Melchor, M.; Braga, A. A. C.; Lledós, A.; Ujaque, G.; Maseras, F. Acc. Chem. Res. 2013, 46, 2626.

[67] Liu, Z.-Q.; Wang, J.-G.; Zhao, Y.-K.; Zhou, B. Adv. Synth. Catal. 2009, 351, 371.

[68] Xu, T.; Hu, X. Angew. Chem., Int. Ed. 2015, 54, 1307.

[69] Che, C.; Zheng, H.-L; Zhu, G.-G. Org. Lett. 2015, 17, 1617.

[70] Chen, X.-Y.; Kong, W.; Cai, H.-T.; Kong, L.-C.; Zhu, G.-G. Chem. Commun. 2011, 47, 2164.

[71] Cai, H.-T.; Yuan, Z.-L.; Zhu, W.-D.; Zhu, G.-G. Chem. Commun. 2011, 47, 8682.

[72] Belhomme, M.; Dru, D.; Xiong, H.; Cahard, D.; Besset, T.; Poisson, T.; Pannecoucke, X. Synthesis 2014, 46, 1859.

[73] Xu, T.; Cheung, C. W.; Hu, X. Angew. Chem., Int. Ed. 2014, 53, 4910.

[74] For more examples of addition of $\mathrm{C}-\mathrm{X}(\mathrm{X}=\mathrm{Cl}, \mathrm{Br}, \mathrm{I})$ bonds to alkynes, see: (a) Ichinose, Y.; Matsunaga, S.-I.; Fugami, K.; Oshima, K.; Utimoto, K. Tetrahedron Lett. 1989, 30, 3155.

(b) Mawson, S. D.; Weavers, R. T. Tetrahedron 1995, 51, 11257.

(c) Tang, Y.; Li, C.-Z. Org. Lett. 2004, 6, 3229.

(d) Kippo, T.; Fukuyama, T.; Ryu, I. Org. Lett. 2010, 12, 4006.

(e) Li, J.-X.; Yang, S.-R.; Wu, W.-Q.; Qi, C.-R.; Deng, Z.-X.; Jiang, H.-F. Tetrahedron 2014, 70, 1516.

(f). Yeh, M.-C. P.; Lin, H.-H.; Kuo, S.-F.; Chen, P.-J.; Hong, J.-W. Adv. Synth. Catal. 2014, 356, 3816

(g) Wallentin, C.-J.; Nguyen, J. D.; Finkbeiner, P.; Stephenson, C. R. J. J. Am. Chem. Soc. 2012, 134, 8875.

(h) Arceo, E.; Montroni, E.; Melchiorre, P. Angew. Chem., Int. Ed. 2014, 53, 120648.

(i) Iwai, T.; Fujihara, T.; Terao, J.; Tsuji, Y. J. Am. Chem. Soc. 2012, 134, 1268.

(j) Goossen, L. J.; Rodríguez. N.; Goossen, K. Angew. Chem., Int. Ed. 2009, 48, 9592.

[75] Fukuyama, Y.; Nakahara, M.; Minami, H.; Kodama, M. Chem. Pharm. Bull. 1996, 44, 1418.

[76] Sakai, A.; Aoyama, T.; Shioiri, T. Tetrahedron Lett. 1999, 40, 4211.

[77] Sasai, A.; Aoyama, T.; Shioiri, T. Heterocycles 2000, 52, 643.

(Zhao, C.) 